\title{
Article
}

\section{The Regulation of Non-Specific Membrane Permeability Transition in Yeast Mitochondria under Oxidative Stress}

\author{
Elena P. Isakova *, Olga I. Klein and Yulia I. Deryabina
}

check for updates

Citation: Isakova, E.P.; Klein, O.I.; Deryabina, Y.I. The Regulation of Non-Specific Membrane Permeability Transition in Yeast Mitochondria under Oxidative Stress. Microbiol. Res. 2021, 12, 419-439. https://doi.org/ 10.3390/microbiolres12020029

Academic Editor: Valery Dembitsky

Received: 25 February 2021

Accepted: 20 April 2021

Published: 1 May 2021

Publisher's Note: MDPI stays neutral with regard to jurisdictional claims in published maps and institutional affiliations.

Copyright: (c) 2021 by the authors. Licensee MDPI, Basel, Switzerland. This article is an open access article distributed under the terms and conditions of the Creative Commons Attribution (CC BY) license (https:/ / creativecommons.org/licenses/by/ $4.0 /)$.
Research Center of Biotechnology of the Russian Academy of Sciences, A.N. Bach Institute of Biochemistry, Leninsky Ave. 33/2, 119071 Moscow, Russia; klein_olga@list.ru (O.I.K.); yul_der@mail.ru (Y.I.D.)

* Correspondence: elen_iss@mail.ru; Tel.: +7-(495)-954-4008

\begin{abstract}
In this study, the mechanism of non-specific membrane permeability (yPTP) in the Endomyces magnusii yeast mitochondria under oxidative stress due to blocking the key antioxidant enzymes has been investigated. We used monitoring the membrane potential at the cellular (potentialdependent staining) and mitochondrial levels and mitochondria ultra-structural images with transmission electron microscopy (TEM) to demonstrate the mitochondrial permeability transition induction due to the pore opening. Analysis of the yPTP opening upon respiring different substrates showed that NAD $(\mathrm{P}) \mathrm{H}$ completely blocked the development of the yPTP. The yPTP opening was inhibited by 5-20 $\mathrm{mM} \mathrm{P}_{\mathrm{i}}, 5 \mathrm{mM} \mathrm{Mg}^{2+}$, adenine nucleotides (AN), $5 \mathrm{mM} \mathrm{GSH}$, the inhibitor of the $\mathrm{P}_{\mathrm{i}}$ transporter $(\mathrm{PiC}), 100 \mu \mathrm{M}$ mersalyl, the blockers of the adenine nucleotide transporter (ANT) carboxyatractyloside (CATR), and bongkrekic acid (BA). We concluded that the non-specific membrane permeability pore opens in the E. magnusii mitochondria under oxidative stress, and the ANT and PiC are involved in its formation. The crucial role of the $\mathrm{Ca}^{2+}$ ions in the process has not been confirmed. We showed that the $\mathrm{Ca}^{2+}$ ions affected the yPTP both with and without the $\mathrm{Ca}^{2+}$ ionophore ETH129 application insignificantly. This phenomenon in the E. magnusii yeast unites both mitochondrial unselective channel ( ${ }_{s c}$ MUC) features in the Saccharomyces cerevisiae mitochondria and the classical membrane pore in the mammalian ones (mPTP).
\end{abstract}

Keywords: Endomyces magnusii; mitochondria; permeability transition; yeast; antioxidant enzymes; reactive oxygen species

\section{Introduction}

Non-specific membrane transition in animal mitochondria (mPTP) is a sudden increase in permeability of the inner mitochondria membrane for the compounds of $\mathrm{Mr} \leq 1500 \mathrm{Da}[1,2]$. The main features of the phenomenon have been investigated for about 40 years, since its discovery in heart mitochondria by Haworth and Hunter in 1979 [3-5]. Currently, it is considered that if the $\mathrm{Ca}^{2+}$ ions are bound under pathological conditions, namely oxidative stress, de-energization, depletion of the intra-mitochondria adenine nucleotides (AN), $\mathrm{Ca}^{2+}$ overload during ischemia/reperfusion, and some others, the complex can open a cyclosporin A (CsA)-sensitive membrane pore with a diameter of 2.6-2.9 nm. It can pass the compounds with a low molecular weight, followed by the release of the accumulated $\mathrm{Ca}^{2+}$, pyridine nucleotides depletion, mitochondria depolarization, and the ATP synthesis block, which resulted in high amplitude mitochondria swelling, the release of pro-apoptotic proteins, and complete damage of cell physiology [6,7]. The mPTP opening is currently known as one of the pathways for active cation efflux from animal mitochondria upon high loading, with cytosolic $\mathrm{Ca}^{2+}$ [8] being an initial event to launch the apoptosis key reactions in animal cells [9]. The regulation of $\mathrm{mPTP}$ has been thoroughly studied. Besides a specific blocker of CsA, working in sub-micromolar concentrations upon non-specific transition [10,11], $\mathrm{Mg}^{2+}$ ions and the AN are considered pore inhibitors [12,13], as well as polyamines [14-17] and bongkrekic acid (BA) [3]. Carboxyatractyloside (CATR) [14,15], 3-hydroxybutyrate/polyphosphate [16], and fatty acids [17], along with the $\mathrm{Ca}^{2+}$ and $\mathrm{P}_{\mathrm{i}}$ 
ions, are regarded as MPTP inducers. The regulatory features of the MPTP permitted investigating its structure and composition. The pore's molecular composition and architecture are being studied in some leading laboratories; however, they remain unknown. Non-specific transition is supposed to be provided by a multi-protein complex, which is composed of an anion channel in an outer mitochondrial membrane (VDAC), ANT, and cyclophilin D (CyPD), as well as hexokinase and proteins Bcl-2 [18,19].

The recent studies corroborated the ANT participation in the $\mathrm{Ca}^{2+}$-induced permeability transition. In the paper [20], the authors using the $\mathrm{Ca}^{2+}$ uptake capacity in the mitochondria from mouse liver, which were Ant1, Ant2, and Ant4 deficient, showed a significant inhibition of mPTP induction. Another component, namely the phosphate carrier (PiC), was proposed by Andrew Halestrap [21]. However, genetic experiments using a mouse model with Slc25a3 deletion in the PiC gene showed that the PiC is not a requisite $\mathrm{mPTP}$ component, although its depletion significantly blunts the response to $\mathrm{Ca}^{+2}$ challenge, leading to desensitization of the pore complex [22]. In the early 2000s, some researchers have proposed an entirely different model of the MPTP, where the pore is formed from no specific proteins but rather due to the aggregation of misfolded integral membrane proteins damaged by oxidative and some other stresses [23]. However, the proposed model explains no mechanism of the MPTP fine regulation by natural modulators and inducers, as well as $\mathrm{Ca}^{2+}$ and $\mathrm{pH}$. In recent studies, a new model of the mPTP was shown based on the $\mathrm{F}_{0} / \mathrm{F}_{1}$-ATP-synthase dimer formation, first proposed by Paolo Bernardi [24]. According to the hypothesis, the non-specific membrane mitochondria transition pore complex includes matrix cyclophilin $\mathrm{D}$ (CyPD), which binds the lateral stalk of the $F_{0} / F_{1}-A T P$ synthase $[24,25]$. It is worth noting that $F_{0} / F_{1}$-ATP-synthase forms supramolecular dimer complexes in the inner mitochondria membrane (IMM), closing their trans-membrane $\mathrm{F}_{0}$-domains. Dimer location of $\mathrm{F}_{0} / \mathrm{F}_{1}$-ATP-synthase contributes to the morphology of the mitochondria, organizing it for the energy-transduction bioenergetics processes. $\mathrm{F}_{0} / \mathrm{F}_{1}$-ATP synthase can maintain a catalyzing activity of ATP hydrolysis by binding a natural $\mathrm{Mg}^{2+}$ cofactor or any other bivalent cations. Some recent data show that the $\mathrm{F}_{0} / \mathrm{F}_{1}$-ATP synthase directly participates in mPTP forming. Modeling the molecular dynamics of the ( $\alpha \beta)$ 3-OSCP complex (oligomycin sensitivity conferral protein) in the $\mathrm{F}_{1}$ domain convincingly proves that the incorporation of $\mathrm{Ca}^{2+}$ into catalytic centers of the enzyme if $\mathrm{Ca}^{2+}$ substitutes $\mathrm{Mg}^{2+}$ undergoes some confirmation changes that transfer the $\mathrm{F}_{0}$ domain from hydrophilic $\mathrm{F}_{1}$ sector to the IMM. Thus, dimer dissociation, namely two membrane $\mathrm{F}_{0}$-domains separation, results in $\mathrm{mPTP}$, which forms at their separation border, changing the cristae shape in the IMM $[18,26]$. Thus, dimer disassembly during $\mathrm{MPTP}$ opening reduces the IMM cambering, which leads to the cristae retraction and changes in the mitochondria morphology. Several key proteins interact with $\mathrm{F}_{0} / \mathrm{F}_{1}$-ATP synthase, including the $\mathrm{Bcl}-2$ family member $\mathrm{Bcl}-\mathrm{xL}$ and $\mathrm{CyPD}$, which is connected with the stator region, OSCP, and possibly with some other subunits [27]. The key role of the $\mathrm{F}_{0} / \mathrm{F}_{1}$-ATP in forming $\mathrm{MPTP}$ was partly corroborated by its inhibition by CsA as well as the high affinity of CsA for CyPD, being a protein related to the F1FO ATP synthase [27].

Currently, the multiple hypothesis is trying to explain the contradictory data: (1) $F_{0} / F_{1}$ ATP synthase can regulate mPTP by changing crista morphology and ADP level, (2) $\mathrm{F}_{0} / \mathrm{F}_{1}$ ATP-ase and ANT can form two pores through the IMM, (3) ANT and $\mathrm{F}_{0} / \mathrm{F}_{1}$-ATP synthase could be demanded for the right formation of the MPTP [28].

The study of non-specific membrane transition in yeast mitochondria also has a dramatic history. Dennis Jung et al. [29], using the S. cerevisiae mitochondria, stated that no classical mPTP was similar to that in animal ones. The authors showed that yeast mitochondria possess the $\mathrm{Ca}^{2+}$-insensitive, CsA-insensitive pore, which is induced upon the substrates oxidation and at the presence of ATP simultaneously. They referred to the PTP in the yeast mitochondria as YMUC. The regulation and molecular composition of YMUC have still been under comprehensive discussion. However, most researchers accept both a complete insensibility of the yeast mitochondria pore to the specific inhibitor of mPTP CsA and Pi's powerful inhibition. The effectors of ANT impact on YMUC just 
opposite to the MPTP, i.e., ATP and BA open YMUC [30,31], whereas for the mammal mitochondria, their inhibitory actions were shown [32]. The role of $\mathrm{Ca}^{2+}$ in the YMUC opening is not quite clear, as it prevents PTP in the S. cerevisiae yeast [33]. However, the forced rapid load of the yeast mitochondria with $\mathrm{Ca}^{2+}$ using the $\mathrm{Ca}^{2+}$-ionophore ETH129 triggers the YMUC opening [34]. The composition of YMUC has not been defined yet. Manuel Gutierrez-Aguilar et al. [35], using the S. cerevisiae null-mutants in the PiC, proved that the $\mathrm{PiC}$ is a requisite component in the YMUC channel formation. In Akiko Yamada's presentation [34], the authors demonstrated that under some experimental conditions, the $S$. cerevisiae mitochondria can display evident signs of inner membrane permeability, such as high amplitude swelling and cytochrome $\mathrm{c}$ release.

Thus, yPTP may be hardly considered a classical analog of the mammal one. A contradictory composition of the mitochondrial pore complex does not permit the regulation and high species peculiarities in many ascomycetes to assay completely, which is likely to be the main problem for a definition of the non-specific permeability transition in the yeasts. If one manages to solve the problem, yPTP could be a useful model and tool for studying the molecular structure of the $\mathrm{mPTP}$. The E. magnusii mitochondria possess a unique $\mathrm{Ca}^{2+}$ uptake system that includes an independent pathway for cation uptake and its release from the loaded mitochondria [36-38]. AN, $\mathrm{Mg}^{2+}$ ions, and polyamines finely regulate both $\mathrm{Ca}^{2+}$ uniporter work and its independent pathway of the efflux from the mitochondrial matrix. Additionally, the E. magnusii yeast, being an obligate aerobe, possesses a full respiratory system similar to the animal ones that makes it a unique tool for studying the mechanisms of membrane transport. In the yeast with a fermentative metabolism type, namely S. cerevisiae, the membrane and mitochondrial apparatus is ill-developed. There are only scant large mitochondria with small cristae. Their yeast mitochondria have fewer and irregular cristae. However, the yeast of pronounced aerobic metabolism, namely E. magnusii, possesses a well-developed membrane system with abundant complicated mitochondria with numerous well-pronounced cristae. All the obtained results define the study's novelty, which allows the authors to introduce new elements into the knowledge of non-specific permeability of the yeast mitochondria.

In our studies [36], we found that under various conditions inducing endogenous oxidative stress (in the presence of some inhibitors and pro-oxidants as well as if $\mathrm{Ca}^{2+}$ is overloaded), which led to crucial damages in animal mitochondria intactness (mPTP), in the E. magnusii yeast, there were no signs of high-amplitude swelling, massive $\mathrm{Ca}^{2+}$ efflux, and decline in the $\Delta \Psi$. However, our latest studies showed that upon blocking the vital antioxidant enzymes (CATs and SODs), the E. magnusii mitochondria's activity displayed some evident signs of mPTP, followed by the damage to cell physiology [39]. Using the isolated mitochondria, we showed that inhibition of the antioxidant systems under oxidative stress caused the $\Delta \Psi$ collapse and nearly double increase in the mitochondria volume. It corroborated the results obtained before at the cellular level. Moreover, we were able to show that the observed phenomenon was accompanied by typical signs of early apoptosis such as chromatin marginalization, cytosolic vacuolization, and cytosolic membrane distortion [39]. Later, we found that full and robust action of cell antioxidant protective systems is the foundation stone for complete mitochondria functioning and consequently normal cellular physiology under oxidative stress during the aging of the culture [40].

In this study, we try to reveal the mechanism of the yPTP induced by oxidative stress in the E. magnusii mitochondria and identify the participants in the process of membrane permeability transition upon inhibiting the major antioxidant systems of a yeast cell. 


\section{Materials and Methods}

\subsection{Yeast Strain and Culture Conditions}

The E. magnusii yeast was grown in agitated Ehrlenmeyer flasks in batches of $100 \mathrm{~mL}$ in glycerol ( $1 \%$ ) containing a medium of the following composition ( $\mathrm{g} / \mathrm{L}): \mathrm{MgSO}_{4}-0.5$, $\left(\mathrm{NH}_{4}\right)_{2} \mathrm{SO}_{4}-0.3, \mathrm{KH}_{2} \mathrm{PO}_{4}-8.6, \mathrm{NaCl}-0.1, \mathrm{CaCl}_{2}-0.05$, yeast extract-2.0, L-histidine$2.75 \mathrm{mg}$, L-methionine- $2.75 \mathrm{mg}$, and L-tryptophan-2.75 $\mathrm{mg}$ at $28^{\circ} \mathrm{C}$ as described previously [40]. $\mathrm{pH}$ was adjusted with $2 \mathrm{M} \mathrm{K}_{2} \mathrm{HPO}_{4}$ to 5.5. Absorbance was assessed in cell suspension at the wavelength of $590 \mathrm{~nm}\left(\mathrm{~A}_{590}\right)$ using a Specol-11 spectrophotometer (Carl Zeiss, Oberkochen, Germany). Cells were harvested at the late exponential $\left(\mathrm{A}_{590}=2.6-2.7\right)$ stage of growth.

\subsection{Respiration Assessment}

Oxygen consumption by the yeast mitochondria was monitored in vitro at $+25^{\circ} \mathrm{C}$ using a Clark-type electrode covered by a fluoroplastic film at a constant potential of $660 \mathrm{mV}$. The incubation medium contained $0.6 \mathrm{M}$ mannitol, $1 \mathrm{mM}$ Tris phosphate ( $\mathrm{pH} 7.4), 1 \mathrm{mM}$ EDTA, $20 \mathrm{mM}$ pyruvate, $5 \mathrm{mM}$ malate, and mitochondria corresponding to $0.3-0.5 \mathrm{mg}$ protein $/ \mathrm{mL}$. All shown data traces are representative of four to six replicates. Rate 4 is the respiration rate in state 4 (initial respiration) before $\left(4_{\mathrm{L}}\right)$ and after the phosphorylation cycle $\left(4_{\mathrm{Ch}}\right)$; rate 3 is the rate in state 3 (the phosphorylation after the ADP addition). The efficacy of oxidative phosphorylation and the degree of the mitochondrial intactness were assayed using the parameters of respiratory control (RC) [38]. We calculated the controls according to Chance $\left(\mathrm{RC}_{\mathrm{Ch}}\right)$ and Lardy $\left(\mathrm{RC}_{\mathrm{L}}\right)$ as the ratios of the respiratory rates in state 3 to those in state 4 (before ADP addition, Chance) and (after phosphorylation cycle, Lardy).

\subsection{Potential-Dependent Staining}

Potential-dependent staining of mitochondria in the E. magnusii cells raised in the late exponential growth phase was performed using rhodamine (Rh123). Cells were incubated with $0.5 \mu \mathrm{M}$ Rh123 and examined in $0,15,20$, and $30 \mathrm{~min}$. The incubation medium contained 0.01 M phosphate saline buffer (PBS), pH 7.4, and 1\% glycerol. Regions of high mitochondrial polarization are indicated by red fluorescence due to the concentrated dye. To examine the Rh123-stained preparations, filters 02 and 15 (Zeiss, Oberkochen, Germany) were used (magnification $\times 100$ ). The photos were taken using an AxioCam MRC camera (Microvisioneer, Esslingen am Neckar, Germany).

\subsection{Isolation of Mitochondria}

Mitochondria were isolated using the method described in [37] with minor modifications. The mitochondria thus obtained met all known criteria of physiological intactness, as inferred from high respiratory rates and ADP/O ratios close to their theoretically expected maxima. Mitochondria were fully active for at least $4 \mathrm{~h}$ after being isolated when kept on ice. Briefly, cells were harvested at different growth phases, washed twice with ice-cold water, resuspended $(0.1 \mathrm{~g}$ wet cells $/ \mathrm{mL})$ in pre-spheroplast buffer $(50 \mathrm{mM}$ Tris- $\mathrm{HCl}$ buffer; $\mathrm{pH}$ 8.6, $4 \mathrm{mM}$ dithiothreitol), incubated at room temperature for 10-15 $\mathrm{min}$, and then diluted with ice-cold water, pelleted at $3000 \times g$ for $10 \mathrm{~min}$, washed twice to remove excess dithiothreitol, and incubated at $28^{\circ} \mathrm{C}$ using gentle stirring for 15-20 min in spheroplast buffer (10 mM HEPES-buffer, pH 7.2, 1.1 M sorbitol) with Novozym $20 \mathrm{~T}$ from Trichoderma harzianum (Sigma-Aldrich, Saint-Luis, MO, USA) (2.5 mg/g cells) and lytic enzymes from snail gut juice (50 mg/g cells). Spheroplast formation was monitored by measuring the osmotic fragility in distilled water. The spheroplasts were rapidly cooled, pelleted by centrifugation at $3000 \times g$ for $10 \mathrm{~min}$, washed gently twice in a post-spheroplast buffer $(1.2 \mathrm{M}$ sorbitol, $5 \mathrm{mM} \mathrm{MgSO}_{4}, \mathrm{pH}$ adjusted to 7.2$)$, resuspended (0.1 g wet cells $/ \mathrm{mL}$ ) in a grinding buffer (10 mM Tris-HCl, pH 7.2, containing 0.4 M mannitol, 1 mM EDTA, 0.05 mM EGTA, and $4 \mathrm{mg} / \mathrm{mL}$ BSA), and disrupted in an all-glass Dounce homogenizer (Kontes, Vineland, NJ, USA) with a low clearance pestle. The suspension was diluted with an isolation buffer (10 mM Tris-HCl, pH 7.2, 0.6 M mannitol, 0.05 mM EDTA, 0.05 mM EGTA, and 4 mg/mL 
BSA) and centrifuged at $2000 \times g$ for $10 \mathrm{~min}$. The supernatant was centrifuged once more at $7000 \times g$ for $20 \mathrm{~min}$. The resulting pellet of mitochondria was washed in $10 \mathrm{mM}$ Tris- $\mathrm{HCl}$, $\mathrm{pH} 7.2$, containing $0.6 \mathrm{M}$ mannitol and $4 \mathrm{mg} / \mathrm{mL}$ BSA, resuspended in a smaller volume of the same buffer, and used immediately.

Mitochondrial protein was assayed by Bradford's method [41] with bovine serum albumin as the standard.

\subsection{Mitochondrial Membrane Potential Assay}

$\Delta \Psi$ was measured in isolated mitochondria (corresponding to $0.4 \mathrm{mg}$ protein $/ \mathrm{mL}$ ) with 10-20 $\mu \mathrm{M}$ safranin as a probe with a Hitachi-557 dual-beam spectrophotometer [42]. It was performed using $\lambda_{511}$ and $\lambda_{533} \mathrm{~nm}$ as the measuring and reference wavelength, respectively. The incubation medium contained $0.4 \mathrm{M}$ mannitol, $0.1 \mathrm{M} \mathrm{KCl}, 20 \mathrm{mM}$ Trisacetate, $\mathrm{pH}$ 7.4; $20 \mathrm{mM}$ Tris-pyruvate, $5 \mathrm{mM}$ malate, and mitochondria corresponding to $0.4 \mathrm{mg}$ protein $/ \mathrm{mL}$. All data traces shown are representative of at least four to six analytical replicates.

\subsection{Transmission Electron Microscopy (TEM)}

TEM analysis of untreated E. magnusii yeast cells was performed as described previously [36]. Briefly, the yeast cells raised in different growth phases were precipitated, fixed with $2.5 \%$ glutaraldehyde in $0.1 \mathrm{M}$ sodium phosphate buffer ( $\mathrm{pH} 7.2$ ) for $2 \mathrm{~h}$, and then post-fixed in $1 \% \mathrm{OsO}_{4}$ for an hour at room temperature. After dehydration, the samples were embedded in Epon 812. Ultrathin sections were prepared with an LKB-8800 ultratome (LKB-Produkter AB, Stockholm-Bromma, Sweden) using diamond knives. Thereafter, the sections were stained with uranyl acetate for $60 \mathrm{~min}$ and post-stained, as described previously [39], and examined with a Jeol (JEM-100B) and Hitachi U-12 electron microscopes (Hitachi, Tokyo, Japan).

\subsection{ROS Generation Assay}

The dynamics of mitochondria ROS production were monitored using the spectroscopic fluorescence probe of 10-acetyl-3,7-dihydroxyphenoxazine, Amplex Red (AR, Hydrogen Peroxide/Peroxidase Assay Kit, Sigma-Aldrich, Saint-Luis, MO, USA), which in the presence of peroxidase reacts with $\mathrm{H}_{2} \mathrm{O}_{2}$ to produce the red-fluorescent oxidation product, resorufin. A stock solution of $10 \mathrm{mM}$ AR in dimethyl sulfoxide was added to the mitochondria to a final concentration of $25 \mu \mathrm{M}$. The suspension was incubated in the medium containing $0.4 \mathrm{M}$ mannitol, $0.1 \mathrm{M} \mathrm{KCl}, 20 \mathrm{mM}$ Tris-acetate, $\mathrm{pH}$ 7.4, $20 \mathrm{mM}$ Tris-pyruvate, $5 \mathrm{mM}$ malate, and mitochondria corresponding to $0.4 \mathrm{mg}$ protein $/ \mathrm{mL}$. The reaction was triggered by the application of horseradish peroxidase $(\mathrm{RZ}=0.6=150-170 \mathrm{U} / \mathrm{mg})$, using a stock solution of $1 \mathrm{mg} / \mathrm{mL}$. The fluorescence was detected for $15 \mathrm{~min}$ using dual-wavelength photometry at $\lambda_{530 \pm 35}\left(\lambda_{\mathrm{ex}}\right) / \lambda_{590 \pm 25}\left(\lambda_{\mathrm{em}}\right) \mathrm{nm}$ with a Synergy 2 (BioTek, Winooski, VT, USA) microplate photofluorometer at a relative sensitivity of 100 followed by data analysis in Microsoft Excel. The dynamics of the peroxide generation rate were nonlinear for the first $10 \mathrm{~min}$ due to the development of the highest level of fluorescence reaching a plateau in $15 \mathrm{~min}$. Therefore, the AR fluorescence level was assessed in 15 min incubation of mitochondria and correlated with the AR fluorescence level after the addition of fresh hydrogen peroxide solution $(100 \mathrm{nmol} / \mathrm{mL}$, positive control).

\subsection{Statistical Analysis}

The experiments were performed in biological triplicates with a standard error of less than $5 \%$ between the replicates. The Student $t$-test was used to analyze the significance of differences for independent samples. Values were considered significant at $p<0.05$. Data are presented as the average \pm the standard deviation in biological triplicates with a standard error of less than 5\%. The influence of the antioxidant enzyme inhibitors on respiration rates and ROS level was estimated using Statistica version 8.0 (StatSoft Inc., Tulsa, OK, USA). A one-way analysis of variance (ANOVA) followed by Duncan's 
protected least significant difference (LSD) test was applied to examine differences between amendment types at probability level $p=0.05$.

\section{Results}

\subsection{Influence of the Key Antioxidant Enzyme Inhibitors on Mitochondria Coupling Features}

All the isolated yeast mitochondria demonstrated a high level of intactness, as seen from high respiratory rates in respiration state 3 and relatively high respiratory RC (Table 1). At first, we studied the effects of the inhibitors on respiration rates of the E. magnusii mitochondria to exclude any non-specific impact of the reagents studied. Table 1 shows that the addition of the CATs inhibitor $4 \mathrm{mM} \mathrm{ATZ} \mathrm{did} \mathrm{not} \mathrm{influence} \mathrm{the} \mathrm{respiration} \mathrm{rate}$ of the mitochondria either in state 2 (the initial respiration in resting state) or in state 3 (stationary phosphorylation upon ADP addition). Moreover, the inhibitors' application affected no mitochondria respiratory controls serving as a marker of tightly coupled mitochondria (Table 1). The inhibitor of the other key ROS scavenging enzyme SODs, 4-5 mM DDC being applied to the mitochondria provoked an insignificant (not more than 5-6\%) increase in the respiration rates, which can be related to its slight uncoupling effect on the mitochondria (Table 1). Nevertheless, the obtained results showed no pronounced decline in the yeast mitochondria, causing some increase in respiratory ratio parameters according to both Lardy and Chance.

Then, the assay of CATs and SODs inhibitors' effects on functional mitochondria states displayed no important influence.

Table 1. The effect of the antioxidant enzyme inhibitors on E. magnusii yeast mitochondria coupling features.

\begin{tabular}{cccc}
\hline $\begin{array}{c}\text { Mitochondrial } \\
\text { Respiration Stage }\end{array}$ & $\begin{array}{c}\text { Respiration Rate } \\
\text { Control }\end{array}$ & $\begin{array}{c}\text { Respiration Rate } \\
\text { (+4 mM ATZ) }\end{array}$ & $\begin{array}{c}\text { Respiration Rate } \\
\text { (+4 mM DDC) }\end{array}$ \\
\hline State $4_{\mathrm{L}}$ & $19.6 \pm 0.63$ & $19.56 \pm 1.39$ & $20.78 \pm 1.04$ \\
State 3 & $42.04 \pm 0.08$ & $42.81 \pm 1.76$ & $44.25 \pm 2.02$ \\
State $44_{\mathrm{Ch}}$ & $16.95 \pm 0.77$ & $16.93 \pm 0.69$ & $15.64 \pm 1.02$ \\
$\mathrm{RC}_{\mathrm{L}}$ & $2.17 \pm 0.12$ & $2.23 \pm 0.12$ & $2.13 \pm 0.08$ \\
$\mathrm{RC}_{\mathrm{Ch}}$ & $2.48 \pm 0.08$ & $2.53 \pm 0.17$ & $2.83 \pm 0.2$ \\
\hline
\end{tabular}

3.2. Generation upon Blocking Antioxidant Enzyme Activities and Influence of $\mathrm{Ca}^{2+}$ Ions on Non-Specific Changes in Yeast Mitochondria Permeability

To check the main non-specific changes in the inner mitochondria membrane permeability, which decrease mitochondrial $\Delta \Psi$ and high-amplitude swelling of mitochondria, we monitored the $\Delta \Psi$ generation and mitochondria configuration upon inhibiting cell antioxidant enzymes CATs and SODs. Respiring mitochondria could keep the transmembrane potential constant for a long time, more than $600 \mathrm{~s}$ (Figure 1A). To analyze the $\mathrm{Ca}^{2+}$ effect on the antioxidant enzyme inhibitors, the mitochondria membrane potential upon respiring on the pyruvate and malate system was monitored in the presence of these agents (Figure 1A). It was shown that $4 \mathrm{mM} \mathrm{ATZ}$ and $4 \mathrm{mM}$ DDC immediately declined the $\Delta \Psi$ to about $13 \%$, followed by a slow but irreversible collapse of the $\Delta \Psi$ up to $50 \%$ (of the initial level) within $300 \mathrm{~s}$ after the addition of the inhibitors (Figure 1A). To assay the impact of $\mathrm{Ca}^{2+}$ ions on the non-specific changes in the mitochondrial membrane, we studied the effect of high cation load $(500 \mu \mathrm{M})$ on the maintenance of the $\Delta \Psi$ by the yeast mitochondria. When $500 \mu \mathrm{M} \mathrm{Ca}^{2+}$ was added $100 \mathrm{~s}$ before the application of the inhibitors, it caused a similar effect. However, ATZ and DDC combined action added after $\mathrm{Ca}^{2+}$ promoted a more rapid decline in the $\Delta \Psi$ (faster than $120 \mathrm{~s}$ ). Unlike the control, it induced its sudden and complete collapse, which could not be restored by suspension aeration or any other additions (Figure 1A). While being added after the inhibitors, $500 \mu \mathrm{M} \mathrm{Ca}^{2+}$ had no influence on the action of the inhibitors (Figure S1). Furthermore, no significant effect of $\mathrm{Ca}^{2+}$ on the changes in mitochondria volume was obtained if the antioxidant enzyme inhibitors (Figure S2) were added. The E. magnusii mitochondria have a unique 
system of $\mathrm{Ca}^{2+}$ ions uptake including the independent pathways of cation uptake and its efflux from the loaded mitochondria [38,43]. As we can see in the curves of the $\mathrm{Ca}^{2+}$ ions load, if $75 \%$ of $100 \mu \mathrm{M}$ cation is loaded in the presence of $20 \mathrm{mM}$ acetate, it leads to the massive efflux from the mitochondria (Figure 1B). It could decrease the sensitization of the non-specific pore complex to the $\mathrm{Ca}^{2+}$ ions. Simultaneously, using $2 \mathrm{mM} \mathrm{P}_{\mathrm{i}}$ as a penetrating anion provided no immediate efflux of $\mathrm{Ca}^{2+}$ from the mitochondrial matrix (Figure 1B) but could serve as the factor inhibiting the non-specific changes [6]. Based on the results, we assayed the effect of the calcium ionophore ETH-129 transporting $\mathrm{Ca}^{2+}$ via an electrogenic mechanism, unlike both A23187 and ionomycin, which functions in a charge-neutral manner [44]. Figure 1C shows that the combined application of $\mathrm{Ca}^{2+}$ and ETH129 to the mitochondria upon blocking the antioxidant enzymes impacts insignificantly on the decrease in the mitochondria membrane potential. We assayed the effect of the $\mathrm{Ca}^{2+}$ on blocking the ROS scavenging enzymes at the cellular level using potential-dependent fluorescent staining of the E. magnusii cells (Figure 1D). For it, we used potentiometric fluorescent dyes of rhodamine 123 (Rhod123), MitoTracker Red, CM- $\mathrm{H}_{2} \mathrm{XRos}$, and JC-1. Figure 1D demonstrates the micro-images of the yeast cells stained with Rhod123, where the intact mitochondria in the energized cells were bright red. At large $(\times 100)$ magnification, numerous bright-fluorescent mitochondria are the most club-shaped, which indicated a high energy potential of the culture under these conditions. The cell population exposed to the antioxidant enzyme inhibitors for 30-60 min showed that most cells (nearly $90 \%$ ) were de-energized significantly (Figure 1D). The pre-incubation of the cells with $0.5-1.0 \mathrm{mM}$ $\mathrm{Ca}^{2+}$ led to a decrease in fluorescence intensity compared to that in the control (Figure 1D). However, no total deenergization was observed. When the yeast cells were treated with the cytochrome oxidase inhibitor, the potassium cyanide, the negative control, showed no energization of mitochondria (Figure 1D). We could see some shadows of cells with hardly visible contours in the micro-images, which appeared due to non-specific Rhod123 adsorption on the cellular surface. It is noteworthy to say that all the experiments showed negative staining with PI, confirming neither necrotic damages of the plasmic membrane nor distortion of cellular physiology (Figure S3).

Thus, we showed that the inhibitors of the antioxidant systems caused the mitochondria $\Delta \Psi$ collapse without the essential influence of the application of the $\mathrm{Ca}^{2+}$ ions.

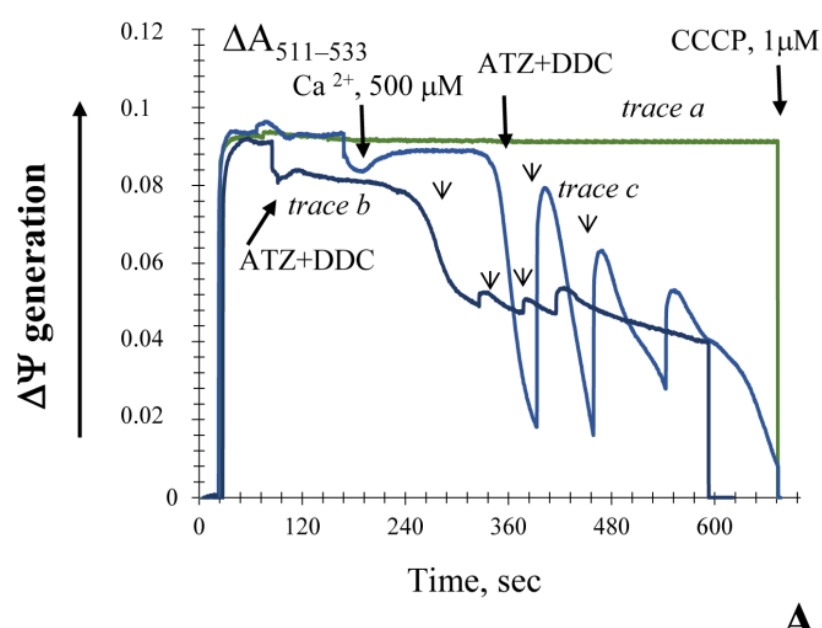

$\mathbf{A}$

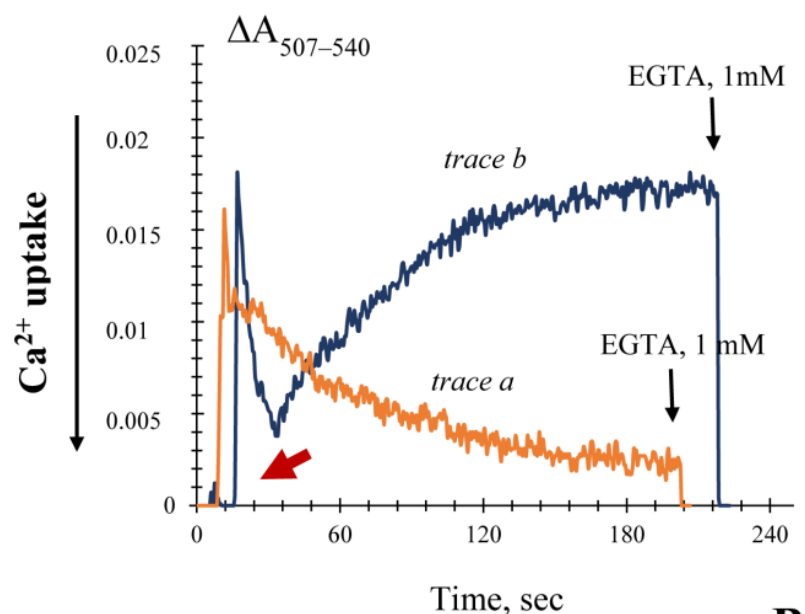

B

Figure 1. Cont. 

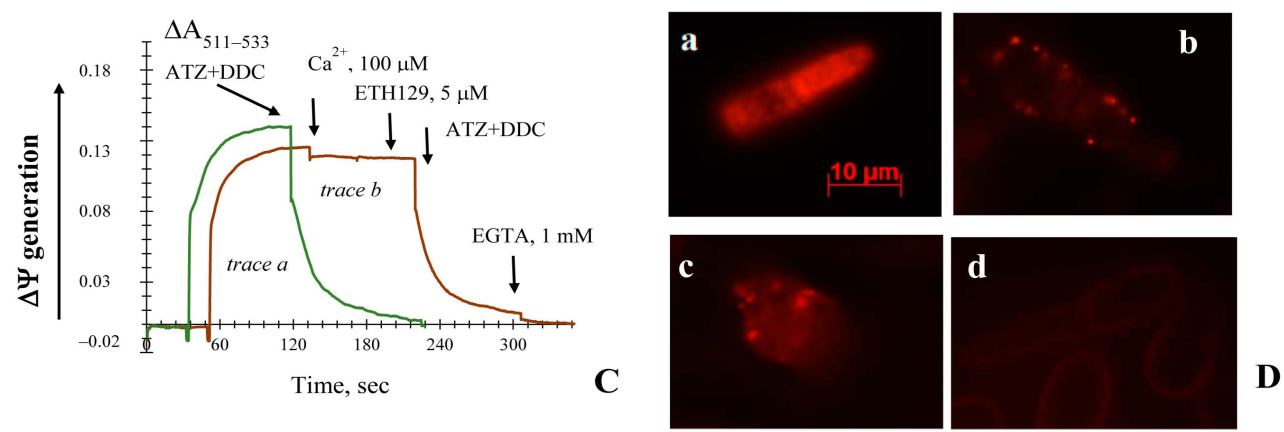

Figure 1. Effects of $\mathrm{Ca}^{2+}, \mathrm{ATZ}$, and DDC on the $\Delta \Psi$ generated by the E. magnusii mitochondria respiring on a pyruvate + malate system. Additions and amounts are given in the figure by large arrows. Panel (A): Incubation medium contained $0.4 \mathrm{M}$ mannitol, $0.1 \mathrm{M} \mathrm{KCl}, 20 \mathrm{mM}$ Tris-acetate, $20 \mu \mathrm{M}$ safranin, $\mathrm{pH} 7.4$, and $0.4 \mathrm{mg}$ of mitochondria protein. Trace a-control; trace $\mathrm{b}$ shows the effect of the addition of $500 \mu \mathrm{M} \mathrm{Ca}^{2+}$ on the $\Delta \Psi$ if the ions are taken up; trace c-the effect of a combined action of $4 \mathrm{mM} \mathrm{ATZ}$ and $4 \mathrm{mM}$ DDC on the membrane potential. Small arrows indicate stirring for aeration. Panel (B): trace a shows $100 \mu \mathrm{M} \mathrm{Ca}^{2+}$ uptake. The medium was the same as that in Panel (A); instead of $20 \mu \mathrm{M}$ safranin, $50 \mu \mathrm{M}$ murexide was added; trace $\mathrm{b}$ shows $100 \mu \mathrm{M} \mathrm{Ca}^{2+}$ uptake in the same medium as that in trace a. The red arrow indicates the $\mathrm{Ca}^{2+}$ addition. Panel (C) incubation medium was the same as that in Panel (A). Trace a shows the effect of the addition of $4 \mathrm{mM}$ DDC and $4 \mathrm{mM} \mathrm{ATZ}$; trace $\mathrm{b}$ shows the effect of the addition of $100 \mu \mathrm{M} \mathrm{Ca}^{2+}$ followed by a combined action of $5 \mu \mathrm{M}$ ETH129, $4 \mathrm{mM}$ DDC, and $4 \mathrm{mM}$ ATZ. Small arrows indicate the stirring for aeration. Panel (D): Micro-images of the potential-dependent stained' mitochondria in the E. magnusii cells raised in the mid-exponential growth phase using Rh123. The regions of high mitochondrial polarization are bright red due to concentrated dye. $a-$ control, magnification $100 \times$; , c-cells were pre-treated with both $4 \mathrm{mM} \mathrm{ATZ}$ and $4 \mathrm{mM} \mathrm{DDC}$ for $30 \mathrm{~min}$, magnification 100×; c-the incubation medium contained $1 \mathrm{mM} \mathrm{Ca}^{2+}$; d-incubation medium contained $2 \mathrm{mM} \mathrm{KCN}$. To examine the Rh123-stained preparations, filters of 02 and 15 (Zeiss) were used (magnification $\times 100$ ). The photos were taken using an AxioCamMR camera. Figure $1 \mathrm{~A}$ has been published in [37].

3.3. The Non-Specific Changes of Permeability Transition in the Yeast Mitochondria upon Using Different Respiratory Substrates

Five main substrate systems were under study: pyruvate and malate and $\alpha$-ketoglutarate, being oxidized via NADH-ubiquinone-oxidoreductase (Complex I of the respiratory system); $\alpha$-glycerol-phosphate and $\mathrm{NAD}(\mathrm{P}) \mathrm{H}$, which are the substrates of the alternative $\mathrm{NAD}(\mathrm{P}) \mathrm{H}$-oxidoreductases oxidizing $\mathrm{NAD}(\mathrm{P}) \mathrm{H}$ in the cytosol; and succinate, being the substrate of the succinate dehydrogenase (non-phosphorylating Complex II of the respiratory system). $\alpha$-Glycerol-phosphate appeared to generate a low membrane potential in the yeast mitochondria, half as much as that in the yeast mitochondria respiring pyruvate and malate, the $\Delta \Psi$ was kept not longer than for $150 \mathrm{~s}$ and irreversibly decreased (Figure S4). Based on the results, we could suppose that the mitochondrial glycerol-phosphate dehydrogenase in the E. magnusii mitochondria is of low activity, and the substrate itself is non-preferable. Oxidation of the pyruvate and malate system showed that yeast mitochondria could keep high $\Delta \Psi$ constant for longer than $600 \mathrm{~s}$ (Figure 1A). The application of ATZ and DDC led to an instant and complete collapse of the potential and insensitive to aeration (Figure 1A). Screening of the membrane potential upon oxidation of $\alpha$-ketoglutarate (Figure 2A) displayed similar dynamics; however, the $\Delta \Psi$ generation was one and half times higher than that upon oxidizing the pyruvate and malate system (Figure 1A). It is noteworthy to say that total action of the inhibitors provoked the decline of the membrane potential up to $30 \%$ of the initial level, and it was more gradual and slow (Figure $2 \mathrm{~A}$ ). Succinate oxidation could keep the $\Delta \Psi$ at a high level during the whole experiment (Figure 2B). However, ATZ and DDC, the blocker of CATs and Cu-Zn-SOD, respectively, induced a more rapid decline of the $\Delta \Psi$ (Figure $2 \mathrm{~B}$ ). 
The addition of NADPH to the mitochondria provided high $\Delta \Psi$ generation at nearly the same level as that upon oxidizing NAD-related substrates (Figure 2C). Application of the inhibitors of antioxidant systems caused no total collapse of potential upon using this substrate (Figure $2 \mathrm{C}$ ). The $\Delta \Psi$ generation upon applying NADPH to the mitochondria was not very high. However, it was extremely resistant to the inhibition of CATs and $\mathrm{Cu}-\mathrm{Zn}-\mathrm{SOD}$, as well as in the case of NADH oxidation (Figure 2D).

Thus, the nature of oxidized substrates did not appear to affect the non-specific permeability transition induced by antioxidant enzyme inhibition. NADPH was the only exception, and its oxidation ensured stable mitochondria permeability and essentially decreased the damage of membrane intactness caused by oxidative stress.
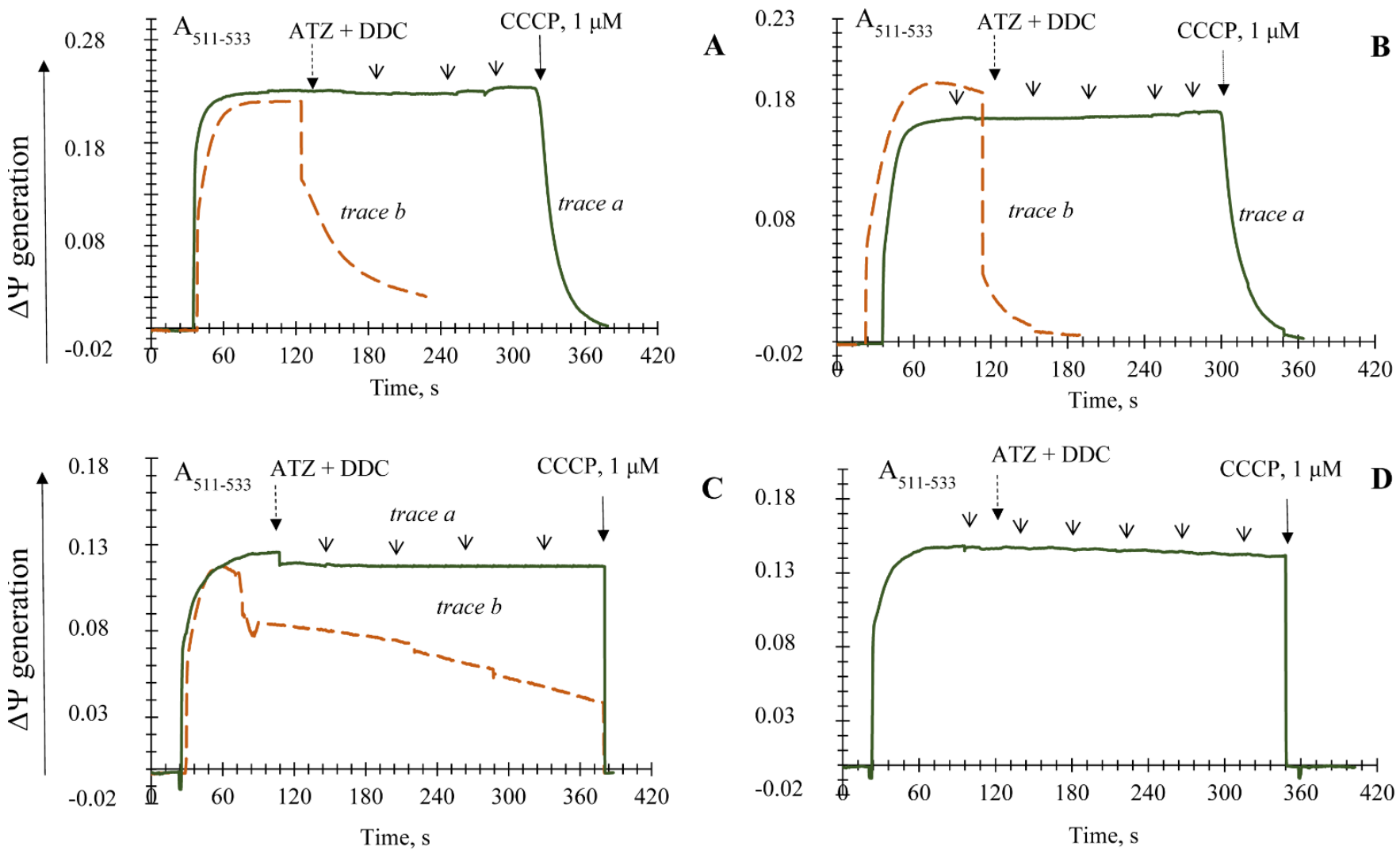

Figure 2. Recording of $\Delta \Psi$ generated by the E. magnusii mitochondria respiring on a $20 \mathrm{mM} \alpha$-ketoglutarate (Panel (A)), $10 \mathrm{mM}$ succinate (Panel (B)), $10 \mathrm{mM}$ NADPH (Panel (C)), and $10 \mathrm{mM}$ NADH (Panel (D)). The incubation medium contained $0.4 \mathrm{M}$ mannitol, $0.1 \mathrm{M} \mathrm{KCl}, 20 \mathrm{mM}$ Tris-acetate, $0.4 \mathrm{mg}$ of mitochondria protein, and $\mathrm{pH} 7.4$. Additions and amounts are indicated by large arrows. Trace $a$-control (solid line); trace $b$ indicates the effect of the addition of $4 \mathrm{mM} \mathrm{DDC,} \mathrm{and} \mathrm{of}$ $4 \mathrm{mM}$ ATZ (dashed line). The additions are indicated by arrows: the solid one for protonophore, $1 \mu \mathrm{M}$ CCCP; the dashed one for ATZ and DDC. Small arrows indicate stirring for aeration.

\subsection{The Effect of Pi and Mersalyl on the Non-Specific Mitochondrial Permeability Transition in the E. magnusii Yeast}

In the E. magnusii mitochondria respiring on pyruvate and malate, $5 \mathrm{mM} \mathrm{P}_{\mathrm{i}}$ significantly inhibited de-energization of the mitochondria induced by the oxidative stress (Figure 3A), whereas 2 and $4 \mathrm{mM} \mathrm{P} \mathrm{P}_{\mathrm{i}}$ were much less efficient (Figure 3A). The addition of $5 \mathrm{mM} \mathrm{P} \mathrm{i}_{\mathrm{i}}$ not only reduced the decline rate more than 10-fold, but also provided its stability at the level of about $43 \%$ of the initial one (Figure $3 \mathrm{~A}$ ). Of note, Pi's effect was less pronounced upon $\alpha$-ketoglutarate oxidation and was negligible upon succinate one (Figure S5). 
Mercurial sodium mersalyl is known to be a potent inhibitor of the phosphate transporter into mitochondria [45]. However, since the observed level of $\Delta \Psi$ is supported by both continuous work of the respiratory chain and ATP synthesis, and $2.5 \mathrm{mM}$ mersalyl is a powerful inhibitor of oxidative phosphorylation in mitochondria, we tested the effect of minimal concentration of mersalyl $(100 \mu \mathrm{M})$ on the non-specific permeability transition in the mitochondria. We revealed that with the background of a slow potential decrease, the effect of antioxidant enzyme inhibitors was smoothed (Figure 3B) and could be compared to that of $2 \mathrm{mM} \mathrm{P}_{\mathrm{i}}$ (Figure 3A).

Thus, we showed that the $\mathrm{PiC}$ inhibitor and $\mathrm{P}_{\mathrm{i}}$ had a powerful inhibitory effect on the non-specific mitochondrial permeability transition in the E. magnusii yeast.

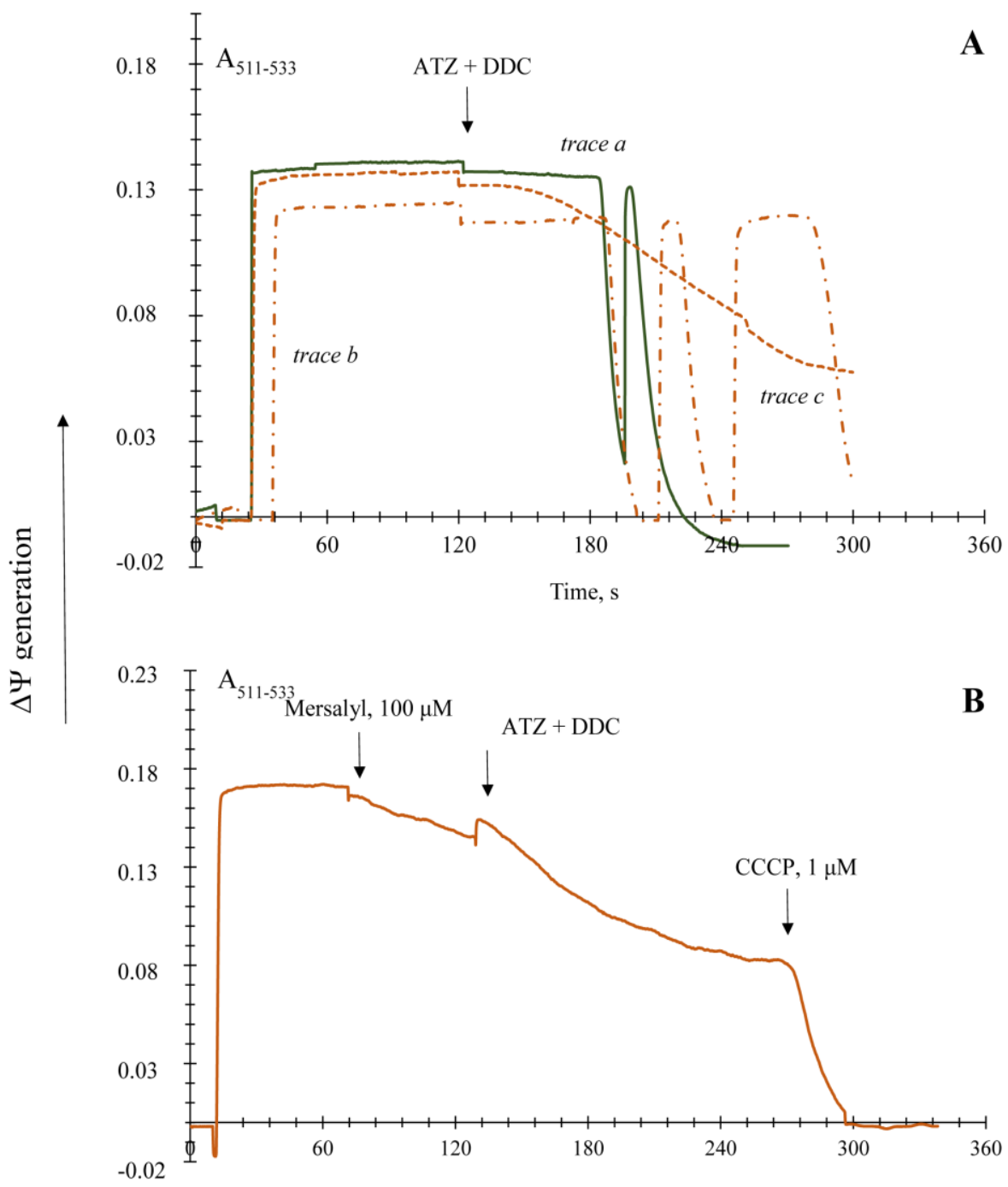

Figure 3. Effects of phosphate $(\mathrm{Pi})$ and mersalyl on non-specific permeability transition induction in the E. magnusii mitochondria respiring on a pyruvate and malate system in the presence of the antioxidant enzyme inhibitors. The incubation medium was the same as that in Figure 1, Panel (A): incubation medium contained also $2 \mathrm{mM}$ Pi (trace a), $4 \mathrm{mM}$ Pi (trace b), and $5 \mathrm{mM}$ Pi (trace c); Panel (B): $100 \mu \mathrm{M}$ mersalyl was added into the medium before the inhibitors. Addition of the inhibitors mixture (4 $\mathrm{mM}$ DDC and $4 \mathrm{mM} \mathrm{ATZ}$ ) is indicated by the arrow.

3.5. The Effect of Different Known Modulators of the mPTP on the Non-Specific Mitochondrial Permeability Transition in the Yeast

The effect of AN definitely depends on the substrate's nature (Figure 4). Its impact was relatively weak upon succinate oxidation (Figure $4 \mathrm{C}$ ), whereas upon $\mathrm{NAD}^{+}$-related substrates $150 \mu \mathrm{M}$ ADP 6.34-fold slowed the rate of the $\Delta \Psi$ decline and prevented it from 
a complete collapse upon pyruvate and malate system oxidation (Figure 4A). ADP addition was hardly efficient upon $\alpha$-ketoglutarate oxidation (Figure 4B). The ATP influence also differed upon various substrate oxidation: it was insignificant upon pyruvate and malate system oxidation (Figure 4A), 1.6-fold decreased the decline rate, and reduced deenergization of the mitochondria by $60 \%$ (Figure $4 \mathrm{~B}$ ). The influence of the ANT inhibitors on the non-specific mitochondrial permeability transition induced by the antioxidant enzyme inhibitors application showed that upon pyruvate and malate system oxidation, both inhibitors CATR and BA blocked the $\Delta \Psi$ decline (Figure 4D). BA looked more efficient. Its addition decreased the de-energization rate by about 3.7-fold and inhibited the membrane potential collapse by $30 \%$ (Figure $4 \mathrm{D}$ ), whereas CATR decreased these parameters 2.23 -fold and by $19 \%$, respectively (Figure $4 \mathrm{D}$ ).
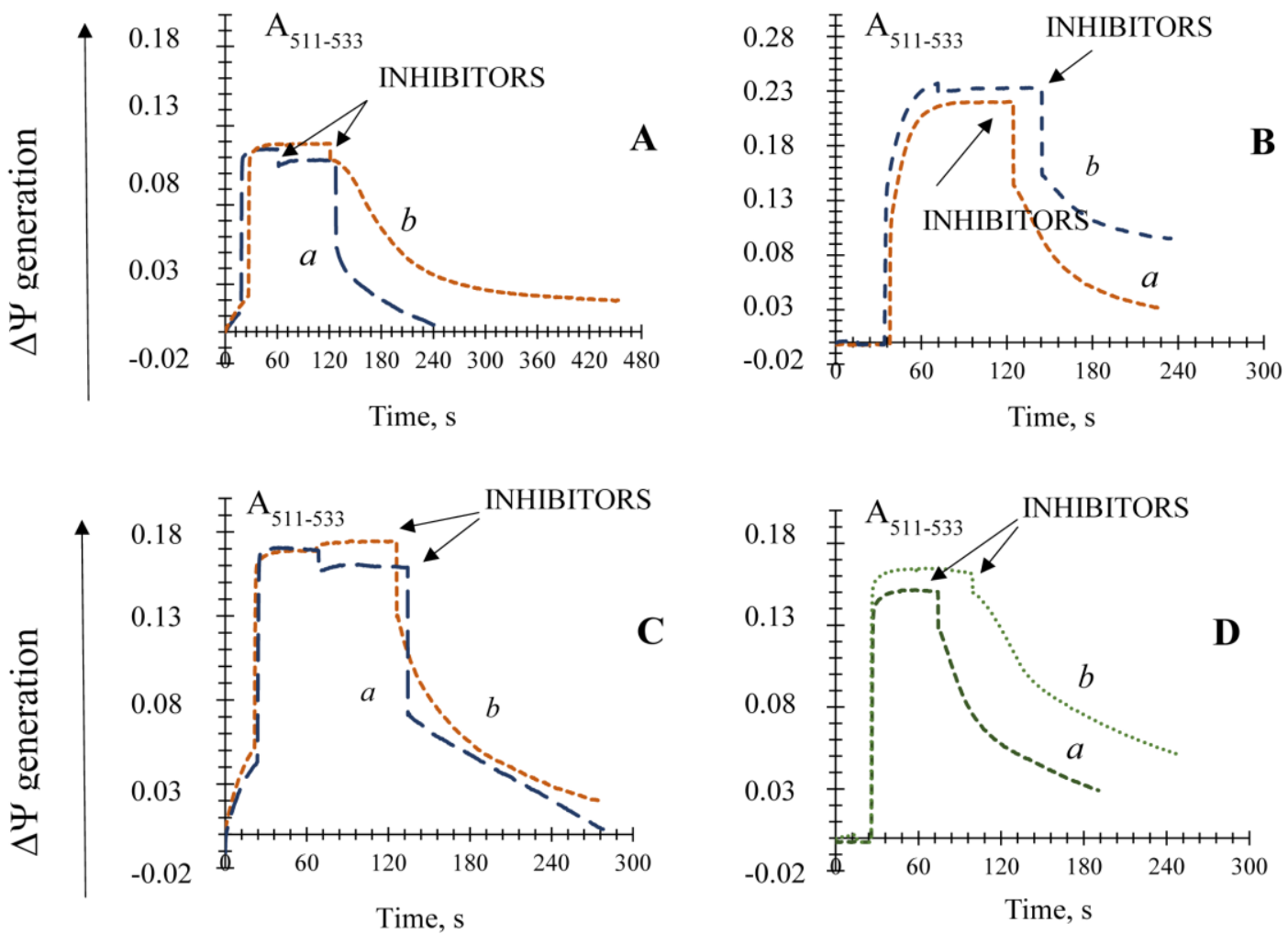

Figure 4. Effects of AN and the inhibitors of the ANT on the non-specific permeability transition induction in the E. magnusii mitochondria respiring on a pyruvate and malate system. (Panel (A)); $\alpha$ ketoglutarate (Panel (B)), and succinate (Panel (C)) in the presence of the antioxidant enzyme inhibitors. The basic incubation medium also contained $150 \mu \mathrm{M}$ ATP (trace a) and $150 \mu \mathrm{M}$ ADP (trace b). (Panel (D)) the incubation medium also contained $0.4 \mu \mathrm{M}$ CATR (trace a) and $40 \mu \mathrm{M}$ BA (trace b). The addition of the inhibitors mixture ( $4 \mathrm{mM}$ DDC and $4 \mathrm{mM} \mathrm{ATZ}$ ) is indicated by the arrows.

$\mathrm{Mg}^{2+}$ and polyamines are also powerful inhibitors of MPTP in animals [33] and strongly promoted the $\Delta \Psi$ decrease by oxidative stress (Figure $5 \mathrm{~A}$ ). It decreased the mitochondria de-energization 3.6-fold and restored the $\Delta \Psi$ up to the level of about $40 \%$ of the initial potential. The polyamines of spermine and spermidine proved rather inefficient, although $40-100 \mu \mathrm{M}$ spermidine was promoted to keep the potential at the level of $25 \%$ of the initial one (Figure 5A).

The well-known antioxidant of $5 \mathrm{mM} \mathrm{N}$-acetylcysteine was applied into the incubation medium either at the stage of the mitochondria de-energization or just before the addition of ROS scavenging enzyme inhibitors. However, no significant results in both experiments were obtained (Figure S6). Nevertheless, the reduced glutathione (GSH) being applied at the concentration of $5 \mathrm{mM}$ completely blocked the non-specific mitochondrial permeability transition upon pyruvate and malate system oxidation (Figure 5B) and provoked the $\Delta \Psi$ decrease only by $35.48 \%$ upon $\alpha$-ketoglutarate oxidation (Figure $5 \mathrm{C}$ ). The inhibitor of 
phospholipase $\mathrm{A}_{2}$ prevented the lipid peroxygenation of the mitochondrial membrane, whereas trifluoroperazine (TFP) also slowed the $\Delta \Psi$ decline rate 3.89-fold, but did not prevent a complete collapse of the potential (Figure S7).
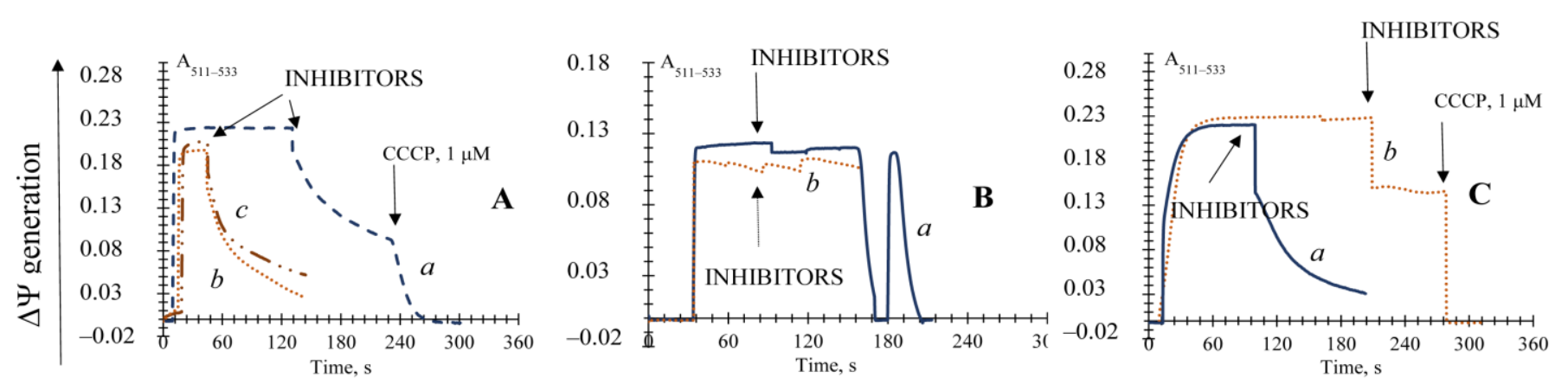

Figure 5. Effects of $\mathrm{Mg}^{2+}$ ions, polyamines, and the GSH on the induction of the non-specific permeability transition in the E. magnusii mitochondria promoted by the application of the antioxidant enzyme inhibitors. Panel (A): the basic incubation medium also contained $5 \mathrm{mM} \mathrm{Mg}^{2+}$ (trace a), 40 or $100 \mu \mathrm{M}$ spermidine (trace b and c, respectively), or $5 \mathrm{mM} \mathrm{GSH}$. The $\Delta \Psi$ was generated by the application of the substrate system (pyruvate + malate) (Panel (B)); $\alpha$-ketoglutarate (Panel (C)); trace a-control; trace b-5 mM GSH was incubated with the 28 mitochondria and applied before the inhibitors' addition. Addition of the inhibitors mixture ( $4 \mathrm{mM}$ DDC and $4 \mathrm{mM}$ ATZ) is indicated by the dashed arrows.

We assayed the actions of two main inhibitors of porin VDAC, erastin and octylguanidine, on their possibility to restore the $\Delta \Psi$ or prevent its collapse due to the block of the antioxidant systems. It was shown that $5.4 \mu \mathrm{M}$ erastin (Figure S8A) and octylguanidine (Figure S8A) were ineffective in inhibiting the membrane potential decline. The inhibitor of ATP-synthase also appeared ineffective for blocking the membrane potential collapse (Figure S8B).

Thus, we showed the inhibitory action of AN, the ANT inhibitors CATR and BA, $\mathrm{Mg}^{2+}$ and polyamines, and GSH on the non-specific mitochondrial permeability transition in the yeast induced by blocking the antioxidant systems.

\subsection{ROS Generation in the Presence of the Effectors of the Non-Specific Mitochondrial Permeability Transition in the Yeast}

The obtained effects of various modulators of the nonspecific mitochondrial permeability were tested to affect the oxygen radicals level in the mitochondria. The ROS assay in the E. magnusii mitochondria showed a high generation of peroxide derivatives of AR in the control, reaching more than 1000 pmoles fluorescence units per $1 \mathrm{mg}$ of mitochondrial protein (Figure 6). In this case, in the positive control, where $100 \mathrm{nmols} / \mathrm{mL}$ hydrogen peroxide was added, the ROS level increased six-fold compared to that in the control mitochondria. The antioxidant systems inhibitors DDC and ATZ, added both separately and together, led to a decrease in the peroxide generation level in the mitochondria by about 20-30\% compared to that in the control (without any other additives) (Figure 6). The effect of the non-specific permeability modulators could be divided into two groups: (1) the ones that affected no ROS level $\left(\mathrm{Mg}^{2+}\right.$ ions, $\left.\mathrm{NAD}(\mathrm{P}) \mathrm{H}\right)$, or did so insignificantly (GSH) in the background of the application of the antioxidant enzyme inhibitors (ATZ+DDC); (2) the modulators with a powerful antioxidant effect $\left(\mathrm{P}_{\mathrm{i}}\right.$, mersalyl, BA, ADP, ATP, $\mathrm{Ca}^{2+}$ ions) (Figure 6). Mersalyl, ATP, and $\mathrm{Ca}^{2+}$, which authentically reduced the rate of ROS generation by $83 \%, 73 \%$, and $69 \%$, respectively, were the most impactful compared to the ATZ + DDC variants (Figure 6). 


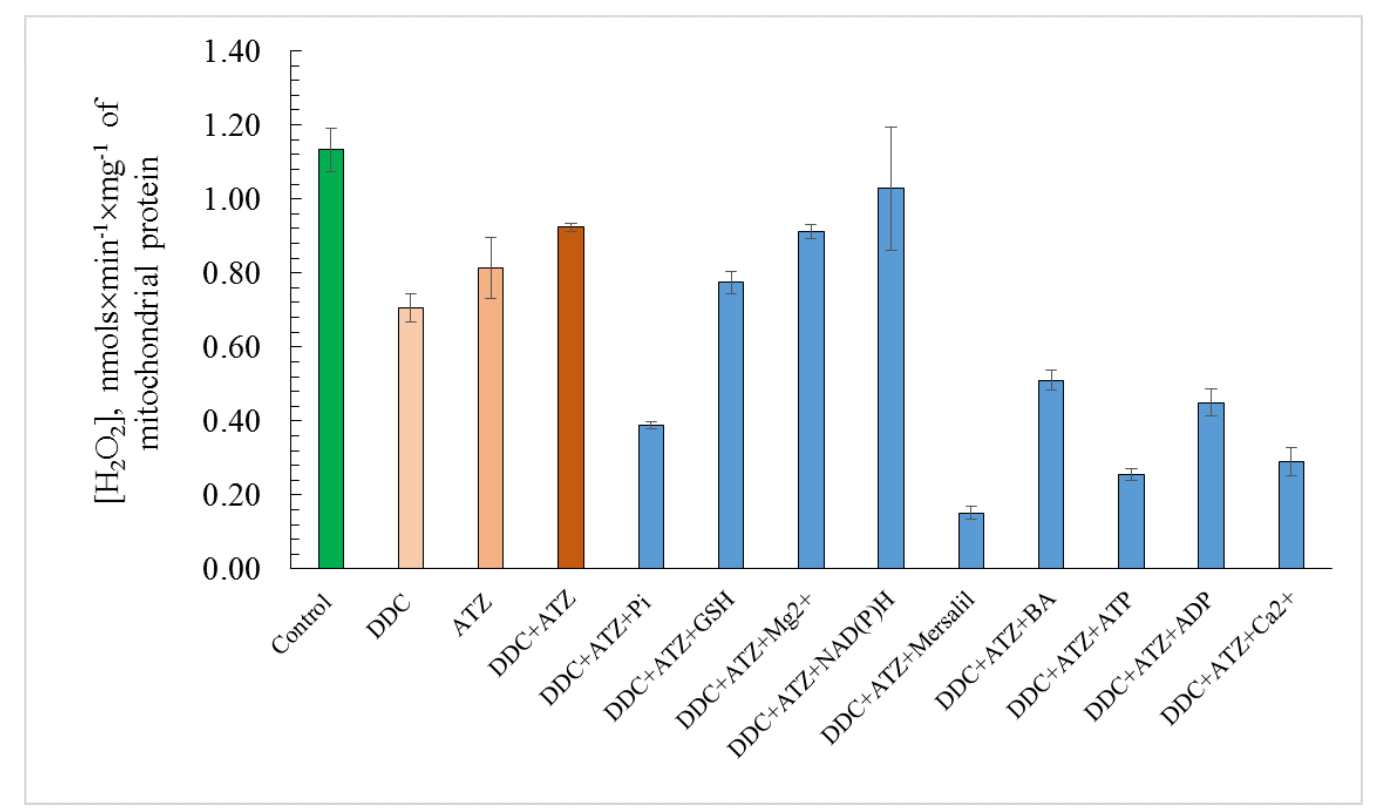

Figure 6. Estimates of total ROS level in E. magnusii mitochondria. The dynamics of intracellular ROS production were monitored using a spectroscopic fluorescence probe of AR. The incubation medium contained $0.4 \mathrm{M} \mathrm{mannitol,} 0.1 \mathrm{M} \mathrm{KCl}$, $20 \mathrm{mM}$ Tris-acetate, $0.4 \mathrm{mg}$ of mitochondria protein, and $\mathrm{pH}$ 7.4. The incubation medium has been amended to indicate $4 \mathrm{mM}$ ATZ, $4 \mathrm{mM}$ DDC, $5 \mathrm{mM} \mathrm{Pi}, 5 \mathrm{mM} \mathrm{GSH}, 5 \mathrm{mM}$ Mg, $10 \mathrm{mM}$ NAD(P)H, $100 \mu \mathrm{M}$ mersalyl, $5 \mu \mathrm{M} \mathrm{BA}, 150 \mu \mathrm{M}$ ATP, $150 \mu \mathrm{M}$ $\mathrm{ADP}$, and $500 \mu \mathrm{M} \mathrm{Ca}^{2+}$. Values are mean \pm S.E.M from 5-6 independent experiments. The intensity of ROS production in the version of "positive control" made up 5.89 pmols $\times \min ^{-1} \times \mathrm{mg}$ of protein ${ }^{-1}$. Values with different letters within a column are significantly different at $p<0.05$.

3.7. The Influence of the Inhibitors of the Non-Specific Permeability Transition on Ultra-Structural Features of the Yeast Mitochondria

We detected the mitochondria volume increase upon applying the vital antioxidant enzyme inhibitors to assay the ultrastructure changes in the yeast mitochondria. We modeled the experiment described in Figure 1A, using the mitochondria, which were exposed to both ATZ and DDC for $5 \mathrm{~min}$. Then, the organelles were fixed and prepared as described in Methods and Materials. It is noteworthy to say that the average mitochondria volume of the control was about $0.83 \mu \mathrm{M}$ (Figure 7A), but it increased nearly twice upon adding the antioxidant enzyme inhibitors (up to $1.43-1.71 \mu \mathrm{M}$ ), disregarding the swollen mitochondria with destroyed cristae (volume of $2.7 \mu \mathrm{M}$, Figure 7A). Micro-images of the mitochondria using TEM showed that the inhibitors' action led to a high increase in the matrix volume, some changes of cristae structure, and even its complete disruption (Figure 7B, indicated with black arrows). The inhibitors of the $\Delta \Psi$ decline due to the addition of both ATZ and DDC caused the total mitochondria volume to decrease by up to $0.6-0.88$ upon the application of $\mathrm{Mg}^{2+}$ and restored GSH (Figure 7C,E, respectively) and up to 1.0-1.4 $\mu \mathrm{M}$ upon $10 \mathrm{mM}$ NADH addition (Figure 7D). Moreover, the addition of $10 \mathrm{mM}$ GSH led to the disruption of some organelles (Figure 7E, indicated by black arrows).

Thus, we corroborated the inhibition of the described modulators on the yeast mitochondria ultra-structure. 


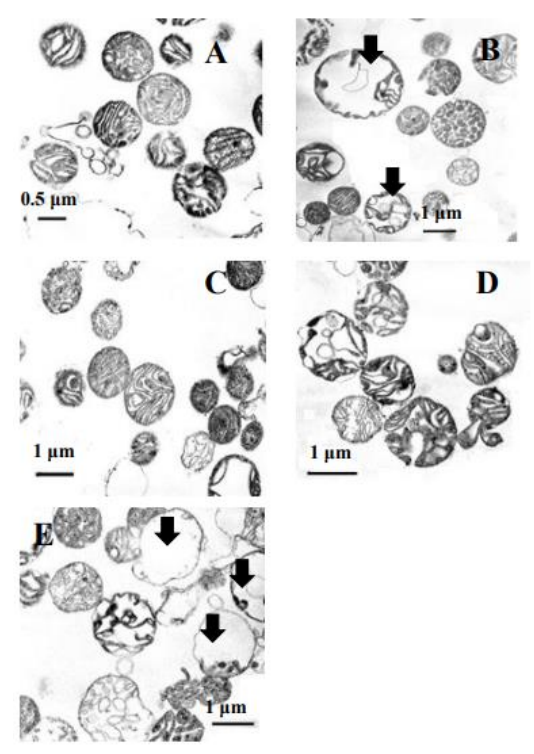

Figure 7. Micro-images of transmission electron microscopy of the E. magnusii mitochondria. (A) - control, (B) - after a 3-min incubation with the antioxidant enzyme inhibitors of $4 \mathrm{mM}$ ATZ and $4 \mathrm{mM}$ DDC; (C) - after a 1-min incubation with $5 \mathrm{mM} \mathrm{Mg}^{2+}$ and $5 \mathrm{mM}$ Pi followed by a 3-min treatment with the antioxidant enzyme inhibitors of $4 \mathrm{mM}$ ATZ and $4 \mathrm{mM} \mathrm{DDC}$; (D)—after a 1-min incubation with10 mM NADH followed by a 3-min treatment with the antioxidant enzyme inhibitors of $4 \mathrm{mM}$ ATZ and $4 \mathrm{mM}$ DDC; (E) -after a 1-minute incubation with $5 \mathrm{mM} \mathrm{GSH}$ followed by a 3-min treatment with the antioxidant enzyme inhibitors of $4 \mathrm{mM} \mathrm{ATZ}$ and $4 \mathrm{mM}$ DDC.

\section{Discussion}

The mechanism of the MPTP complex formation, its architecture, and its composition are under keen discussion and have been studied rather well for animal mitochondria [26-28]. Currently, some evident facts defining the phenomenon of MPTP have been obtained: (1) it is CsA-insensitive [29,35,46]; (2) it is inhibited by $P_{i}[29,46]$; (3) it is induced both upon oxidizing the substrates and in the presence of ATP $[29,35,46] ;(4)$ it does not depend completely on $\mathrm{Ca}^{2+}$ additions [29,46]. Based on the results, we could conclude that the yPTP is not related to any $\mathrm{Ca}^{2+}$ uptake and differs significantly from the classical and well-defined animal mPTP.

In our studies, some aspects of the regulation of non-specific transition induced by antioxidant systems inhibition in the E. magnusii yeast were revealed. We showed that the disruption of mitochondria membrane transition due to antioxidant systems inhibition by ATZ and DDC is specific and is not related to direct distortion in the oxidative phosphorylation (Table 1). Additionally, evident heterogeneity in their effects selective for different organelles was the second important point of observation. The analysis of the mitochondria using TEM showed that some of them (about $40 \%$ of the total number) nearly double increased in the matrix volume with evident distortion of crista configuration (Figure 2B), whereas the rest of the mitochondria showed no significant changes in the ultrastructure. A similar phenomenon was described in Beatrice et al. [47] and Petronilli et al. [48]. It supposes that various sub-populations of mitochondria display different degrees of permeabilization. Our experiments showed the same heterogeneity, which can be explained, on one hand, by different ages and sizes of the organelles in the population, and on the other hand, by different levels of membrane intactness of various mitochondria. Both electron microscopic images and some different rates of $\Delta \Psi$ decline in the mitochondria can corroborate it (Figure 1A; Figure 3).

We have shown earlier that the SODs activity was relatively high and inhibited by $2 \mathrm{mM}$ DDC, a specific inhibitor of the cytosolic SOD, by more than $60 \%$. To distinguish the activities of $\mathrm{Cu} / \mathrm{Zn}-\mathrm{SOD}$ (SOD1), located in the cytoplasm, and Mn-SOD (SOD2), located in the mitochondria matrix, we measured the total enzyme activity in the presence of 
$\mathrm{KCN}$, which inhibits no mitochondrial SOD form, but blocks only the SOD1 form at low concentrations. SOD1 isoform makes up about $60 \%$, whereas SOD2 makes up nearly $40 \%$ [39]. Before, in the E. magnusii mitochondria, we revealed some unknown additional SODs isoforms. One of them matched the activity of a marker enzyme $(\mathrm{Cu} / \mathrm{ZnSOD}$ from bovine erythrocytes). The sensitivity to the inhibitor DDC was different for various enzyme isoforms. Isoforms 1-3 were sensitive to the DDC action, but $4-5$ were sensitive to $\mathrm{KCN}$ and insensitive to DDC. We may suppose that they belong to Mn-SOD (SOD2) [39]. We assume that Mn-SOD in the mitochondria, possibly even in two isoforms, is involved in the ROS detoxification and other antioxidant enzymes, namely glutathione peroxidase 1 , thioredoxin peroxidase- 3 (Trx3), thioredoxin reductase- 2 (Trr2), and peroxiredoxins 3 and 5 . However, SOD1 is known to be responsible for protecting the yeast cells from exogenous oxidative stress. Perhaps, in the E. magnusii mitochondria, some fraction of SOD1 is located in the inter-membrane space [49]. It plays a pivotal role in detoxifying ROS, as the results of our experiments show.

The assay of the ROS generation at the mitochondrial level showed that the application of the antioxidant system inhibitors provoked no jump in endogenous oxygen radicals (Figure 6). At first glance, such an unexpected result could be explained by the DDC and ATZ inhibition of $\Delta \Psi$ generation, presented in all the variants studied, which, in turn, led to the decreased ROS level generated by complexes I and III of the mitochondrial respiratory chain [50]. Cabrera-Orefice and co-authors obtained similar data [46] while studying the regulation of the mitochondrial unselective channel $\left({ }_{s c} \mathrm{MUC}\right)$ in the S. cerevisiae mitochondria. The authors using AR for peroxide detection showed that a pore inhibitor $4 \mathrm{mM} \mathrm{P}_{\mathrm{i}}$ increased the ROS generation rate threefold more if the $s_{c} \mathrm{MUC}$ was closed than that if it was open. The pore blockers, namely the divalent $\mathrm{Ca}^{2+}$ and $\mathrm{Mg}^{2+}$ cations, and the respiratory chain complex III inhibitor antimycin A in the presence of $P_{i}$, also increased the ROS production [46]. Thus, we can assume that in our case, a decrease in the ROS generation upon the open pore is a physiological mitochondria response, which protects them from oxidative stress. Indeed, a certain role of some other antioxidant enzymes located in the mitochondria matrix, which could function as the ROS scavengers causing a decrease in oxygen radicals, cannot be excluded. For example, Mn-dependent SOD, glutathione peroxidase 1, thioredoxin 2, and peroxiredoxins 3 and 5 can [51]. Powerful inhibitors of the non-specific permeability in the yeast mitochondria, namely $\mathrm{GSH}, \mathrm{Mg}^{2+}$ ions, and $\mathrm{NAD}(\mathrm{P}) \mathrm{H}$, did not influence the ROS level, and in some cases even increased it slightly, which could corroborate the speculation (Figure 6).

In the study, $\mathrm{Ca}^{2+}$ ions alone and $\mathrm{Ca}^{2+}$ and the ionophore ETH129 affected insignificantly non-specific changes in the E. magnusii mitochondria, having blocked the antioxidant system (Figure 1C). However, potentiometric staining of yeast cells (Figure 1D) let us conclude that there was no pronounced influence of $\mathrm{Ca}^{2+}$ on the phenomenon upon blocking the antioxidant systems at both the mitochondria and cellular levels. However, the ROS generation decreased nearly fourfold if the cation was added (Figure 8), which cannot exclude its participation in the yPTP openings.

We showed that NAD-dependent substrates (pyruvate and malate and $\alpha$-ketoglutarate) promote different mitochondria sensitivity to the inhibitors of antioxidant systems. The dynamics of membrane permeability changes due to oxidative stress upon oxidizing succinate through complex II of the respiratory chain were similar to that one obtained while oxidizing pyruvate and malate (Figure 3). The data contradict the idea that complex I plays a key role in mPTP regulation and could even be a component of the pore complex [52]. Moreover, $\mathrm{NAD}(\mathrm{P}) \mathrm{H}$ oxidation significantly inhibited the $\Delta \Psi$ decline, promoted by the SODs and CATs inhibition (Figure 2D). It let us assume that the support of electron transport chain function at the expense of the exogenous $\mathrm{NAD}(\mathrm{P}) \mathrm{H}$ oxidation is necessary for keeping redox balance in the mitochondria. Briston and colleagues [53] have investigated the impact of mitochondria substrate availability on the probability of $\mathrm{Ca}^{2+}$-induced $\mathrm{mPTP}$ opening and its consequences. The authors concluded that upon oxidizing the glutamate and malate system, the mPTP opening caused a temporary increase in respiration followed 
by a decrease, which could be restored by the NADH or succinate addition. It was in good agreement with the inhibition of the mitochondria's respiratory activity due to the loss of the matrix NADH. The same mechanism of restoration of the electron transport chain activity could occur in the yeast mitochondria, especially taking into account their high ability to oxidize effectively exogenous NAD(P)H [54].

The results on powerful inhibition of $\mathrm{P}_{\mathrm{i}}$ on the yPTP (Figure $3 \mathrm{~A}$ ) and double decrease of the ROS generation in the yeast mitochondria (Figure 6) agreed well with the data by Yamada et al. [34,46]. They showed that the pore opening in the S. cerevisiae mitochondria was inhibited by high $\mathrm{P}_{\mathrm{i}}$ concentrations. Moreover, in our study, the collapse of mitochondria function was significantly inhibited if a PiC inhibitor, $100 \mu \mathrm{M}$ mersalyl (Figure 3B), was applied. The results may support the hypothesis of the $\mathrm{PiC}$ participation in the pore complex, declared in some papers [55]. Mersalyl influence decreased the ROS generation in the mitochondria by 7.5 times (Figure 6), which corroborated the fact that the closed yPTP decreases endogenous oxidative stress.

The $\Delta \Psi$ decline inhibition in the E. magnusii mitochondria by the antioxidants and mPTP modulators known for the animal mitochondria (polyamines, $\mathrm{Mg}^{2+}$ ions, and exogenous GSH) (Figure 5) was of a different mechanism. The proposed mechanism of polyamines' interaction with the cardiomyocytes' mitochondria under oxidative stress supposes ROS's direct suppression and prevention of apoptotic changes in the myocardium under these conditions [56-58]. A similar effect of polyamines is likely to occur upon blocking antioxidant systems in the yeast mitochondria. As for the $\mathrm{Mg}^{2+}$ ions and exogenous GSH, we observed no significant drop in the ROS levels if they were added (Figure 6). It may indicate some other mechanisms of their action. In particular, GSH can participate in some coupled reactions of glutathione peroxidase 1 (Grx1), the selenium-containing peroxidase, using the compound as a reducing equivalent [59]. Moreover, NAD(P)H participates in the glutathione system reactions, which reductase performs the redox reactions with and possibly potentiates the antioxidant effect of GSH [59]. Antioxidant systems, namely the thioredoxin-peroxidase-3 ( $\operatorname{Tr} x 3)$, thioredoxin-reductase-2 (Trr2), and peroxiredoxins 3 and 5 [50], also function in the yeast mitochondria and may be involved in this process. The $\mathrm{Mg}^{2+}$ ions' action can be directly related to the influence on the pore composition [46].

The drop in the mitochondria potential of E. magnusii induced by the antioxidant systems' inhibition was significantly slowed by low concentrations of $P_{i}, A N$, and the ANT blocker BA, whereas CATR weakly inhibited the decrease. These results are partly consistent with the data by Jung et al., while defining the ATP-induced pore in the $S$. cerevisiae mitochondria [29]. It was also highly dependent on low concentrations of $\mathrm{P}_{\mathrm{i}}$ and ADP; however, it was utterly insensitive to CATR. Our phenomenon features partly agree with a modern concept of the mPTP structural model, which is a complex of hexokinase/VDAC/ANT and may include the outer membrane TSPO (formerly known as peripheral benzodiazepine (Bz) receptor) and Bcl-2 family members [60,61].

The inhibitory effects of AN in our study also confirm the data obtained using the mammal mitochondria that ATP/ADP can significantly reduce the mPTP sensitivity to $\mathrm{Ca}^{2+}$. Moreover, the efficacy of the nucleotides as the MPTP inhibitors depends on their functioning as the ANT substrates [62]. The effects of the ANT inhibitors are within this hypothesis: BA reduces the possibility of the pore opening, while CATR increases it. The BA application significantly decreases the ROS level, which is another argument in favor of the hypothesis (Figure 6).

Our study confirmed no participation of the mitochondrial porin VDAC and the ATPase in the nonspecific membrane permeability transition. However, now it is premature to draw any conclusions about the non-participation of the components in the pore complex. It is known that mersalyl blocks $P_{i}$ transport into mitochondria generally reacting with the $\mathrm{PiC}$ external thiols [63]. Moreover, along with this, it has been shown that monofunctional thiol reagents, in particular, hydrophilic mersalyl and hydrophobic NEM, can interact with both the same and different thiol groups of the inner mitochondrial membrane [64-66] that cannot exclude its participation in any possible components of the pore, and in 
particular, ATP-ase. Some researchers questioned the ATP synthase participation in the $\mathrm{Ca}^{2+}$-dependent non-specific mitochondria permeability $[67,68]$.

In their recent paper, Cabrera-Orefice and co-authors [46] described the non-specific mitochondrial permeability using $S$. cerevisiae, called ${ }_{S c}$ MUC, which appeared at high oxygen uptake rates and was finely inhibited by the $\mathrm{Ca}^{2+}, \mathrm{Mg}^{2+}$, and $\mathrm{P}_{\mathrm{i}}$ ions. According to the authors, the physiological role of the phenomenon is to prevent the ROS overproduction in the mitochondria. The ${ }_{s c}$ MUC activity is dynamically regulated both by the ATP $/ P_{i}$ ratio and by changes in the amount of the bivalent cations that provides a reversible opening/closing of ${ }_{S c} \mathrm{MUC}$ and a concurrent decrease in the ROS production. Our results agreed with those of Cabrera-Orefice et al. and Jung et al. [29,46] concerning the ATPinduced pore in the S. cerevisiae mitochondria. However, we observed no triggering effect of ATP and inhibition by $\mathrm{Ca}^{2+}$ ions. Moreover, on the contrary, AN and the high reducing potential of mitochondria had an inhibitory effect on the yPTP opening. In this study, the inhibition by $\mathrm{Mg}^{2+}$ and $\mathrm{P}_{\mathrm{i}}$ may be related to a direct effect on the pore components, which, as we can assume at the moment, are ANT and PiC.

\section{Conclusions}

Figure 8 shows a hypothetical yPTP pattern in the E. magnusii mitochondria. We suppose that the increase in the ROS level in the mitochondrial matrix, induced by both CATs' and SODs' inhibition, provokes some change in the composition of the putative pore components, in particular, $\mathrm{PiC}$, probably due to the cross-linked Cys159-Cys256 protein (simulated in the experiments by interaction with diamide and phenylarzine oxide). A similar situation occurs if there is an excess of reducing equivalents in the mitochondria respiratory chain under physiological conditions, or under pathological conditions [14]. Moreover, the ANT conformation in the " $\mathrm{C}$ "-position can also trigger the pore opening. The physiological decrease in the ROS production due to their detoxification if the $\mathrm{Mg}^{2+}$ ions and AN are added, and the redox balance restoration due to the glutathione system action at the conjugate participation of $\mathrm{NAD}(\mathrm{P}) \mathrm{H}$, could restore the mitochondria intactness and promote the yPTP closure. Direct inhibition of the pore components by the specific BA inhibitors and mersalyl provides a similar closure in an experimental model (Figure 8). We cannot exclude the participation of any other possible players in this complex. Thus, the pore complex in the yeast mitochondria can be regulated by natural components of a yeast cell, namely $\mathrm{Mg}^{2+}, \mathrm{AN}, \mathrm{P}_{\mathrm{i}}, \mathrm{NAD}(\mathrm{P}) \mathrm{H}, \mathrm{GSH}$, possibly $\mathrm{Ca}^{2+}$ ions, and their ratio, which ensure the yPTP opening and closing upon changing the oxygen radicals level both in the cellular and in the mitochondria matrix. It can be the primary physiological role of this phenomenon. We cannot exclude the concept that there are different models of non-specific membrane distortion in the mitochondria of different yeast species.

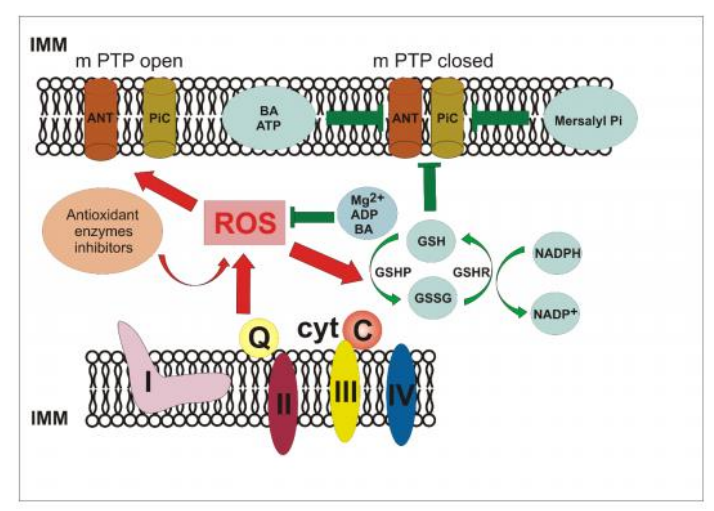

Figure 8. Hypothetic scheme of the yPTP in the E. magnusii mitochondria. 
Supplementary Materials: The following are available online at https:/ / www.mdpi.com/article/ $10.3390 /$ microbiolres12020029/s1, Figure S1: Effects of $\mathrm{Ca}^{2+}, \mathrm{ATZ}$, and DDC on the $\Delta \Psi$ generated by the E. magnusii mitochondria respiring on a pyruvate+malate system., Figure S2: Mitochondria swelling, Figure S3: Fluorescence micro-images of E. magnusii cells raised at the mid-logarithmical growth phase labeled with PI $(100 \mu \mathrm{g} / \mathrm{mL})$, Figure S4: Generation of $\Delta \Psi$ upon oxidation of $\alpha$ glycerophosphate, Figure S5: Effects of $5 \mathrm{mM} \mathrm{P} \mathrm{P}_{\mathrm{i}}$ on non-specific permeability transition induction in the E. magnusii mitochondria respiring on a $\alpha$-ketoglutarate (a) and succinate (b) in the presence of the antioxidant enzymes inhibitors, Figure S6: Effects of $5 \mathrm{mM} \mathrm{N}$-acetylcysteine on non-specific permeability transition induction in the E. magnusii mitochondria respiring on the $\Delta \Psi$ generated by the E. magnusii mitochondria respiring on a pyruvate+malate system in the presence of the antioxidant enzymes inhibitors, Figure S7: Effects of the lipid peroxidation inhibitor, trifluoroperasine (TFP), on the induction of non-specific permeability transition in the E. magnusii mitochondria promoted by the application of the antioxidant enzymes inhibitors, Figure S8: Effect of the inhibitors of VDAC (Panel A) and oligomycin (Panel B) on non-specific permeability transition induction due to antioxidant systems inhibition in the E. magnusii mitochondria, Figure S9: Amperometric recording of oxygen consumption by the E. magnusii mitochondria respiring on pyruvate + malate.

Author Contributions: Conceptualization, Y.I.D.; Formal analysis, E.P.I. and O.I.K.; Investigation, E.P.I. and Y.I.D.; Methodology, E.P.I.; Supervision, Y.I.D.; Writing-original draft, E.P.I. and Y.I.D.; Writing-review \& editing, E.P.I. and Y.I.D. All authors have read and agreed to the published version of the manuscript.

Funding: This study was supported by the State Assignment 0104-2019-0024 to Research Center of Biotechnology RAS.

Acknowledgments: The authors thank Kulikova N. for her help in statistical analysis of the data.

Conflicts of Interest: The authors declare no conflict of interest. The funders had no role in the design of the study; in the collection, analyses, or interpretation of data; in the writing of the manuscript, or in the decision to publish the results.

\section{References}

1. Di Lisa, F.; Bernardi, P. Modulation of Mitochondrial Permeability Transition in Ischemia-Reperfusion Injury of the Heart. Advantages and Limitations. Curr. Med. Chem. 2015, 22, 2480-2487. [CrossRef]

2. Briston, T.; Selwood, D.L.; Szabadkai, G.; Duchen, M.R. Mitochondrial Permeability Transition: A Molecular Lesion with Multiple Drug Targets. Trends Pharmacol. Sci. 2019, 40, 50-70. [CrossRef] [PubMed]

3. Hunter, D.R.; Haworth, R.A. The $\mathrm{Ca}^{2+}$-induced membrane transition in mitochondria. I. The protective mechanisms. Arch. Biochem. Biophys. 1979, 195, 453-459. [CrossRef]

4. Haworth, R.A.; Hunter, D.R. The $\mathrm{Ca}^{2+}$-induced membrane transition in mitochondria. II. Nature of the $\mathrm{Ca}^{2+}$ trigger site. Arch. Biochem. Biophys. 1979, 195, 460-467. [CrossRef]

5. Hunter, D.R.; Haworth, R.A. The $\mathrm{Ca}^{2+}$-induced membrane transition in mitochondria. III. Transitional Ca ${ }^{2+}$ release. Arch. Biochem. Biophys. 1979, 195, 468-477. [CrossRef]

6. Halestrap, A.P.; Richardson, A.P. The mitochondrial permeability transition: A current perspective on its identity and role in ischaemia/reperfusion. J. Mol. Cell Cardiol. 2015, 78, 129-141. [CrossRef]

7. Venditti, P.; Di Meo, S. The Role of Reactive Oxygen Species in the Life Cycle of the Mitochondrion. Int. J. Mol. Sci. 2020, 21, 2173. [CrossRef]

8. Bernardi, P. Mitochondrial transport of cations: Channels, exchangers, and permeability transition. Physiol. Rev. 1999, 79, 1127-1155. [CrossRef]

9. Carraro, M.; Bernardi, P. Calcium and reactive oxygen species in regulation of the mitochondrial permeability transition and of programmed cell death in yeast. Cell Calcium 2016, 60, 102-107. [CrossRef]

10. Fournier, N.; Ducet, G.; Crevat, A. Action of cyclosporine on mitochondrial calcium fluxes. J. Bioenerg. Biomembr. 1987, 19, $297-303$. [CrossRef]

11. Halestrap, A.P.; Davidson, A.M. Inhibition of Ca2(+)-induced large-amplitude swelling of liver and heart mitochondria by cyclosporin is probably caused by the inhibitor binding to mitochondrial-matrix peptidyl-prolyl cis-trans isomerase and preventing it interacting with the adenine nucleotide translocase. Biochem. J. 1990, 268, 153-160. [CrossRef]

12. Halestrap, A.P.; Clarke, S.J.; Javadov, S.A. Mitochondrial permeability transition pore opening during myocardial reperfusion-a target for cardioprotection. Cardiovasc. Res. 2004, 61, 372-385. [CrossRef] 
13. Halestrap, A.P. Calcium, mitochondria and reperfusion injury: A pore way to die. Biochem. Soc. Trans. 2006, 34, 232-237. [CrossRef] [PubMed]

14. Halestrap, A.P.; Brenner, C. The adenine nucleotide translocase: A central component of the mitochondrial permeability transition pore and key player in cell death. Curr. Med. Chem. 2003, 10, 1507-1525. [CrossRef]

15. Halestrap, A.P. A pore way to die: The role of mitochondria in reperfusion injury and cardioprotection. Biochem. Soc. Trans. 2010, 38, 841-860. [CrossRef]

16. Pavlov, E.; Zakharian, E.; Bladen, C.; Diao, C.T.; Grimbly, C.; Reusch, R.N.; French, R.J. A large, voltage-dependent channel, isolated from mitochondria by water-free chloroform extraction. Biophys. J. 2005, 88, 2614-2625. [CrossRef] [PubMed]

17. Sultan, A.; Sokolove, P.M. Palmitic acid opens a novel cyclosporin A-insensitive pore in the inner mitochondrial membrane. Arch. Biochem. Biophys. 2001, 386, 37-51. [CrossRef] [PubMed]

18. Nesci, S. The mitochondrial permeability transition pore in cell death: A promising drug binding bioarchitecture. Med. Res. Rev. 2020, 40, 811-817. [CrossRef]

19. Baines, C.P.; Gutiérrez-Aguilar, M. The still uncertain identity of the channel-forming unit(s) of the mitochondrial permeability transition pore. Cell Calcium 2018, 73, 121-130. [CrossRef]

20. Karch, J.M.; Bround, M.J.; Khalil, H.; Sargent, M.A.; Latchman, N.; Terada, N.; Peixoto, P.M.; Molkentin, J.D. Inhibition of mitochondrial permeability transition by deletion of the ANT family and CypD. Sci. Adv. 2019, 5, eaaw4597. [CrossRef]

21. Leung, A.W.; Varanyuwatana, P.; Halestrap, A.P. The mitochondrial phosphate carrier interacts with cyclophilin D and may play a key role in the permeability transition. J. Biol. Chem. 2008, 283, 26312-26323. [CrossRef]

22. Kwong, J.Q.; Davis, J.; Baines, C.P.; Sargent, M.A.; Karch, J.; Wang, X.; Huang, T.; Molkentin, J.D. Genetic deletion of the mitochondrial phosphate carrier desensitizes the mitochondrial permeability transition pore and causes cardiomyopathy. Cell Death Differ. 2014, 21, 1209-1217. [CrossRef]

23. He, L.; Lemasters, J.J. Regulated and unregulated mitochondrial permeability transition pores: A new paradigm of pore structure and function? FEBS Lett. 2002, 512, 1-7. [CrossRef]

24. Carraro, M.; Checchetto, V.; Szabó, I.; Bernardi, P. F-ATP synthase and the permeability transition pore: Fewer doubts, more certainties. FEBS Lett. 2019, 593, 1542-1553. [CrossRef] [PubMed]

25. Giorgio, V.; von Stockum, S.; Antoniel, M.; Fabbro, A.; Fogolari, F.; Forte, M.; Glick, G.D.; Petronilli, V.; Zoratti, M.; Szabó, I.; et al. Dimers of mitochondrial ATP synthase form the permeability transition pore. Proc. Natl. Acad. Sci. USA 2013, 110, $5887-5892$. [CrossRef] [PubMed]

26. Gerle, C. Mitochondrial F-ATP synthase as the permeability transition pore. Pharmacol Res. 2020, 160, 105081. [CrossRef] [PubMed]

27. Winquist, R.J.; Gribkoff, V.K. Targeting putative components of the mitochondrial permeability transition pore for novel therapeutics. Biochem. Pharmacol. 2020, 177, 113995. [CrossRef] [PubMed]

28. Bonora, M.; Patergnani, S.; Ramaccini, D.; Morciano, G.; Pedriali, G.; Kahsay, A.E.; Bouhamida, E.; Giorgi, C.; Wieckowski, M.R.; Pinton, P. Physiopathology of the Permeability Transition Pore: Molecular Mechanisms in Human Pathology. Biomolecules 2020, 10, 998. [CrossRef]

29. Jung, D.W.; Bradshaw, P.C.; Pfeiffer, D.R. Properties of a cyclosporin-insensitive permeability transition pore in yeast mitochondria. J. Biol. Chem. 1997, 272, 21104-22112. [CrossRef]

30. Prieto, S.; Bouillaud, F.; Ricquier, D.; Rial, E. Activation by ATP of a proton-conducting pathway in yeast mitochondria. Eur. J. Biochem. 1992, 208, 487-491. [CrossRef]

31. Roucou, X.; Manon, S.; Guérin, M. Conditions allowing different states of ATP- and GDP-induced permeability in mitochondria from different strains of Saccharomyces cerevisiae. Biochim. Biophys. Acta 1997, 1324, 120-132. [CrossRef]

32. McStay, G.P.; Clarke, S.J.; Halestrap, A.P. Role of critical thiol groups on the matrix surface of the adenine nucleotide translocase in the mechanism of the mitochondrial permeability transition pore. Biochem. J. 2002, 367, 541-548. [CrossRef]

33. Pérez-Vázquez, V.; Saavedra-Molina, A.; Uribe, S. In Saccharomyces cerevisiae, cations control the fate of the energy derived from oxidative metabolism through the opening and closing of the yeast mitochondrial unselective channel. J. Bioenerg. Biomembr. 2003, 35, 231-241. [CrossRef] [PubMed]

34. Yamada, A.; Yamamoto, T.; Yoshimura, Y.; Gouda, S.; Kawashima, S.; Yamazaki, N.; Yamashita, K.; Kataoka, M.; Nagata, T.; Terada, H.; et al. Ca2+-induced permeability transition can be observed even in yeast mitochondria under optimized experimental conditions. Biochim. Biophys. Acta 2009, 1787, 1486-1491. [CrossRef]

35. Gutiérrez-Aguilar, M.; Pérez-Martínez, X.; Chávez, E.; Uribe-Carvajal, S. Saccharomyces cerevisiae, the phosphate carrier is a component of the mitochondrial unselective channel. Arch. Biochem. Biophys. 2010, 494, 184-191. [CrossRef]

36. Deryabina, Y.I.; Isakova, E.P.; Shurubor, E.I.; Zvyagilskaya, R.A. Calcium-dependent nonspecific permeability of the inner mitochondrial membrane is not induced in mitochondria of the yeast Endomyces magnusii. Biochemistry 2004, 69, 1025-1033. [CrossRef]

37. Bazhenova, E.N.; Saris, N.E.; Zvyagilskaya, R.A. Stimulation of the yeast mitochondrial calcium uniporter by hypotonicity and by ruthenium red Biochim. Biophys. Acta 1998, 1371, 96-100. [CrossRef]

38. Deryabina, Y.I.; Bazhenova, E.N.; Saris, N.E.; Zvyagilskaya, R.A. Ca $\left({ }^{2+}\right)$ efflux in mitochondria from the yeast Endomyces magnusii. J. Biol. Chem. 2001, 276, 47801-47806. [CrossRef] [PubMed] 
39. Deryabina, Y.; Isakova, E.; Antipov, A.; Saris, N.E. The inhibitors of antioxidant cell enzymes induce permeability transition in yeast mitochondria. J. Bioenerg. Biomembr. 2013, 45, 491-504. [CrossRef] [PubMed]

40. Deryabina, Y.; Isakova, E.; Sekova, V.; Antipov, A.; Saris, N.E. Inhibition of free radical scavenging enzymes affects mitochondrial membrane permeability transition during growth and aging of yeast cells. J. Bioenerg. Biomembr. 2014, 46, 479-492. [CrossRef]

41. Bradford, M.M. A rapid and sensitive method for the quantitation of microgram quantities of protein utilizing the principle of protein-dye binding. Anal. Biochem. 1976, 72, 248-254. [CrossRef]

42. Åkerman, K.E.O;; Wikström, M.K.F. Safranine as a probe of the mitochondrial membrane potential. FEBS Lett. 1976, 68, 191-197. [CrossRef]

43. Bazhenova, E.N.; Deryabina, Y.I.; Eriksson, O.; Zvyagilskaya, R.A.; Saris, N.E. Characterization of a high capacity calcium transport system in mitochondria of the yeast Endomyces magnusii. J. Biol. Chem. 1998, 273, 4372-4377. [CrossRef]

44. Wang, E.; Erdahl, W.L.; Hamidinia, S.A.; Chapman, C.J.; Taylor, R.W.; Pfeiffer, D.R. Transport properties of the calcium ionophore ETH-129. Biophys. J. 2001, 81, 3275-3284. [CrossRef]

45. Tyler, D.D. Evidence of a phosphate-transporter system in the inner membrane of isolated mitochondria. Biochem. J. 1969, 111, 665-678. [CrossRef] [PubMed]

46. Cabrera-Orefice, A.; Ibarra-García-Padilla, R.; Maldonado-Guzmán, R.; Guerrero-Castillo, S.; Luévano-Martínez, L.A.; PérezVázquez, V.; Gutiérrez-Aguilar, M.; Uribe-Carvajal, S. The Saccharomyces cerevisiae mitochondrial unselective channel behaves as a physiological uncoupling system regulated by $\mathrm{Ca}^{2+}, \mathrm{Mg}^{2+}$, phosphate and ATP. J. Bioenerg. Biomembr. 2015, 47, 77-91. [CrossRef]

47. Beatrice, M.C.; Stiers, D.L.; Pfeiffer, D.R. Increased permeability of mitochondria during $\mathrm{Ca}^{2+}$ release induced by $t$-butyl hydroperoxide or oxalacetate. The effect of ruthenium red. J. Biol. Chem. 1982, 257, 7161-7171. [PubMed]

48. Petronilli, V.; Cola, C.; Massari, S.; Colonna, R.; Bernardi, P. Physiological effectors modify voltage sensing by the cyclosporin A-sensitive permeability transition pore of mitochondria. J. Biol. Chem. 1993, 268, 21939-21945. [CrossRef]

49. Han, D.; Williams, E.; Cadenas, E. Mitochondrial respiratory chain-dependent generation of superoxide anion and its release into the intermembrane space. Biochem. J. 2001, 353, 411-416. [CrossRef] [PubMed]

50. Handy, D.E.; Loscalzo, J. Redox regulation of mitochondrial function. Antioxid. Redox Signal. 2012, 16, 1323-1367. [CrossRef]

51. Wang, C.H.; Wu, S.B.; Wu, Y.T.; Wei, Y.H. Oxidative stress response elicited by mitochondrial dysfunction: Implication in the pathophysiology of aging. Exp. Biol. Med. 2013, 238, 450-460. [CrossRef]

52. Chauvin, C.; De Oliveira, F.; Ronot, X.; Mousseau, M.; Leverve, X.; Fontaine, E. Rotenone inhibits the mitochondrial permeability transition-induced cell death in U937 and KB cells. J. Biol. Chem. 2001, 276, 41394-41398. [CrossRef] [PubMed]

53. Briston, T.; Roberts, M.; Lewis, S.; Powney, B.; Staddon, J.M.; Szabadkai, G.; Duchen, M.R. Mitochondrial permeability transition pore: Sensitivity to opening and mechanistic dependence on substrate availability. Sci. Rep. 2017, 7, 10492. [CrossRef]

54. Overkamp, K.M.; Bakker, B.M.; Kötter, P.; van Tuijl, A.; de Vries, S.; van Dijken, J.P.; Pronk, J.T. In vivo analysis of the mechanisms for oxidation of cytosolic NADH by Saccharomyces cerevisiae mitochondria. J. Bacteriol. 2000, 182, 2823-2830. [CrossRef] [PubMed]

55. Leung, A.W.; Halestrap, A.P. Recent progress in elucidating the molecular mechanism of the mitochondrial permeability transition pore. Biochim. Biophys. Acta 2008, 1777, 946-952. [CrossRef] [PubMed]

56. Zorov, D.B.; Juhaszova, M.; Sollott, S.J. Mitochondrial reactive oxygen species (RoS) and RoS-induced RoS release. Physiol. Rev. 2014, 94, 909-950. [CrossRef]

57. Yang, Y.; Wang, W.; Xiong, Z.; Kong, J.; Qiu, Y.; Shen, F.; Huang, Z. Activation of SiRT3 attenuates triptolide-induced toxicity through closing mitochondrial permeability transition pore in cardiomyocytes. Toxicol. In Vitro 2016, 34, 128-137. [CrossRef] [PubMed]

58. He, F.; Wu, Q.; Xu, B.; Wang, X.; Wu, J.; Huang, L.; Cheng, J. Suppression of Stim1 reduced intracellular calcium concentration and attenuated hypoxia/reoxygenation induced apoptosis in h9C2 cells. Biosci. Rep. 2017, 37, BSR20171249. [CrossRef] [PubMed]

59. Herrero, E.; Ros, J.; Bel, G.; Cabiscol, E. Redox control and oxidative stress in yeast cells. Biochim. Biophys. Acta 2008, 1780, 1217-1235. [CrossRef] [PubMed]

60. Bernardi, P. The mitochondrial permeability transition pore: A mystery solved? Front. Physiol. 2013, 4, 95. [CrossRef]

61. Bernardi, P.; Di Lisa, F. The mitochondrial permeability transition pore: Molecular nature and role as a target in cardioprotection. J. Mol. Cell Cardiol. 2015, 78, 100-106. [CrossRef]

62. Halestrap, A.P.; Woodfield, K.Y.; Connern, C.P. Oxidative stress, thiol reagents, andmembrane potential modulate the mitochondrial permeability transition byaffecting nucleotide binding to the adenine nucleotide translocase. J. Biol. Chem. 1997, 272, 3346-3354. [CrossRef]

63. Houstěk, J.; Pedersen, P.L. Adenine nucleotide and phosphate transport systems of mitochondria. Relative location of sulfhydryl groups based on the use of the novel fluorescent probe eosin-5-maleimide. J. Biol. Chem 1985, 260, 6288-6295. [CrossRef]

64. Kowaltowski, A.J.; Vercesi, A.E.; Castilho, R.F. Mitochondrial membrane protein thiol reactivity with N-ethylmaleimide or mersalyl is modified by Ca2p: Correlation with mitochondrial permeability transition. Biochim. Biophys. Acta 1997, 1318, $395 \mathrm{e} 402$. [CrossRef]

65. De Palma, A.; Scalera, V.; Bisaccia, F.; Prezioso, G. Citrate uniport by the mitochondrial tricarboxylate carrier: A basis for a new hypothesis for the transport mechanism. J. Bioenerg. Biomembr. 2003, 35, 133-140. [CrossRef] [PubMed]

66. García, N.; Martínez-Abundis, E.; Pavon, N.; Chavez, E. On the opening of an insensitive cyclosporin A non-specific pore by phenylarsine plus mersalyl. Cell. Biochem. Biophys. 2007, 49, 84-90. [CrossRef] [PubMed] 
67. He, J.; Ford, H.C.; Carroll, J.; Ding, S.; Fearnley, I.M.; Walker, J.E. Persistence of the mitochondrial permeability transition in the absence of subunit c of human ATP synthase. Proc. Natl. Acad. Sci. USA 2017, 114, 3409-3414. [CrossRef] [PubMed]

68. Walker, J.E.; Carroll, J.; He, J. Reply to Bernardi: The mitochondrial permeability transition pore and the ATP synthase. Proc. Natl. Acad. Sci. USA 2020, 117, 2745-2746. [CrossRef] [PubMed] 